\title{
ORGANIZACIONES TRANSNACIONALES DE INMIGRANTES Y DESARROLLO: UN ESTUDIO COMPARATIVO
}

\author{
ALEJANDRO PORTES ${ }^{* *}$ \\ CRISTINA ESCOBAR** \\ ALEXANDRIA WALTON RADFORD**
}

TRADUCCIÓN DEL INGLÉS
LUIS RODOLFO MORÁN

Resumen. Este artículo analiza la influencia de las organizaciones de inmigrantes colombianos, dominicanos y mexicanos de la costa este de Estados Unidos en el desarrollo local y nacional de sus países de origen. Mediante la aplicación de una encuesta sistemática y entrevistas, se estudian los contextos de salida y los modos de incorporación en atención a tres hipótesis: 1) la asimilación en el país receptor y la participación en las actividades transnacionales no necesariamente se oponen entre sí; 2) las diferencias en el contexto sociopolítico de salida y el carácter participativo de los gobiernos del país de origen influyen significativamente la forma y actividades de las organizaciones de inmigrantes, y 3) los contextos de llegada también pueden afectar el inicio de las actividades, según la discriminación que afronten los recién llegados.

Palabras Clave. Organizaciones transnacionales de inmigrantes, desarrollo, transnacionalismo.

AbSTRACT. This article analyzes the influence of Colombian, Dominican and Mexican immigrant organizations on the U.S. East Coast on the local and national development of the countries of origin. Through the application of a systematic survey and interviews, the contexts of exit and the modes of incorporation are studied attending to three hypothesis: 1) the assimilation into the receiving country and the participation in transnational activities are not necessarily opposed to each other, 2) differences in the sociopolitical context of departure and participatory character of the country of origin's government significantly influence immigrant organizations' form and activities, 3) the contexts of reception can also affect the start of the activities, depending on the discrimination that the newcomers face.

KEYWORDS. Transnational immigrant organizations, development, transnationalism.

* Para la recolección de datos se contó con el apoyo de un fondo de investigación. Para la redacción del informe, el autor principal dispuso de un apoyo de la Fundación MacArthur y de un fondo para la investigación del Institute for International and Regional Research (PIIRS) de Princeton. Rosario Espinal, de la Temple University, y Lilian Bovea participaron en la investigación y se responsabilizaron del trabajo de campo sobre las organizaciones de dominicanos en Estados Unidos y en República Dominicana. María Jesús Criado, del Instituto Universitario de Investigación Ortega y Gasset de Madrid, aportó un apoyo en las primeras etapas del proyecto. Agradecemos los comentarios de Raúl Delgado Wise, Carlos González Gutiérrez, Scott Lynch y de los dictaminadores de esta revista.

** Center for Migration and Development, Princeton University. 


\section{INTRODUCCIÓN}

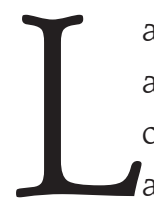

a página de internet 'wWw.conexioncolombia.com), perteneciente a una asociación público-privada de Colombia, se propone difundir información de ese país entre sus emigrantes desperdigados en todo el mundo y, al mismo tiempo, canalizar las contribuciones y proyectos filantrópicos de organizaciones de migrantes. "Con tan sólo pulsar», dice el folleto de Conexión Colombia, "cualquier persona en el mundo puede donar y contribuir al desarrollo del país. iConéctese ahora!» Según la directora ejecutiva de la organización, Diana Sánchez-Rey, la página web es visitada, diariamente, por miles de colombianos de todo el mundo que buscan noticias y narraciones sobre su país, quienes, además, envían sus comentarios: «Principalmente por los migrantes de más edad y recursos radicados en Europa y Estados Unidos, para quienes la nostalgia es más poderosa, [...] pero también por los profesionistas más jóvenes que se fueron recientemente y se sienten obligados con el país que los educó». ${ }^{1}$

A menos de dos millas de las oficinas de Conexión Colombia, Sor Irene, perteneciente a las Hermanas Vicentinas de la Caridad, dirige un refugio para quienes carecen de vivienda en Bogotá, los llamados «habitantes de la calle», la mayoría de ellos con enfermedades mentales, retrazo mental o farmacodependencia. Todas las noches, Sor Irene y sus ayudantes recorren el peligroso barrio que rodea el convento en busca de habitantes de la calle. El refugio les ofrece no sólo protección, comida y ropa, sino también rehabilitación mediante terapia verbal y ocupacional. El equipo empleado en el aprendizaje de nuevas habilidades - desde la producción y venta de papel elaborado con desechos reciclados, hasta la elaboración y venta de pan- ha sido adquirido gracias a las donaciones de los colombianos en el extranjero. ${ }^{2}$

En el mismo convento vive Sor Isabel, una monja que hace quince años ayudó a la creación de un asilo y una escuela para huérfanos en la ciudad de Tunja. Los fondos para la compra del terreno para el asilo, así como para construir los dormitorios y la escuela fueron proporcionados, en su mayoría, por la Fundación del Divino Niño, una organización caritativa fundada por un sacerdote colombiano, un periodista nacido en Tunja junto con una red de inmigrantes y voluntarios de Nueva York y Nueva Jersey. Las computadoras para la escuela fueron donadas por la empresa IBM, gracias a los buenos oficios de la fundación. ${ }^{3}$

\footnotetext{
${ }^{1}$ Entrevista de campo realizada por el autor principal en Bogotá, Colombia, el 15 de marzo de 2005. Los nombres de las personas son ficticios.

${ }^{2}$ Entrevista de campo realizada en Bogotá, Colombia, el 16 de marzo de 2005. Los nombres de las personas son ficticios.

${ }^{3} \mathrm{Idem}$.
} 
Los ejemplos pueden multiplicarse. En todo el hemisferio, en los países y comunidades locales desde donde parten los migrantes hacia el mundo desarrollado, la solidaridad de estas personas y su sentido de obligación hacia quienes se han quedado atrás se han convertido en una fuente confiable, no sólo para la supervivencia de las familias, sino también para la puesta en práctica de toda una gama de proyectos filantrópicos y cívicos. Como es conocido, el monto de las remesas que envían los emigrantes desde los países avanzados hacia sus respectivas naciones sobrepasa, fácilmente, la ayuda extranjera que reciben esos países e, incluso, se equipara con sus ingresos de divisas por exportaciones. En 2004, las remesas recibidas por Guatemala y El Salvador se calculaban en dos mil y tres mil millones de dólares, respectivamente; por Colombia, en cinco mil millones, y, por México, la abrumadora cifra de 16 mil millones. En el continente americano, las remesas alcanzaron los 23 mil millones (Latin America Report, 2003; Cortina y De la Garza, 2004).

Es menos conocida la gran variedad de organizaciones colectivas de inmigrantes que impulsan varios proyectos en sus respectivos países y comunidades de origen, así como las propuestas de estas comunidades e, incluso, de los Estadonación para motivar y canalizar las contribuciones materiales de los expatriados. El aumento de la migración, proveniente del sur hacia el norte del planeta, se ha reconocido como un rasgo de la economía mundial capitalista y de su incesante proceso de integración (Zolberg, 1989; Castles, 2004; Portes y DeWind, 2004). Menos reconocido, hasta hace poco tiempo, es el hecho de que este desplazamiento masivo no se da en un solo sentido, sino que incluye un movimiento de retorno que se ha tornado un importante factor en el desarrollo de los países y regiones de origen. De la misma manera, las comunidades de inmigrantes se convierten en un actor inesperado, aunque cada vez más visible, de la política de sus pueblos y países de origen (Vertovec, 2004; Levitt y Glick-Schiller, 2004).

Transnacionalismo es el nombre con el que se ha bautizado a estas actividades, y que ha influido la literatura sociológica reciente (Portes, Haller y Guarnizo, 2002; Guarnizo, Portes y Haller, 2003). Aún cuando han surgido algunas voces que disienten respecto de la novedad e importancia del fenómeno (Waldinger y Fitzgerald, 2004), el peso de la evidencia empírica aporta una prueba vigorosa acerca del carácter novedoso de estas prácticas y su importancia estructural para las regiones de origen y para las propias comunidades de inmigrantes (Smith, 2003; Vertovec, 2004). La mayor parte de esta evidencia, empero, proviene de estudios de caso de comunidades específicas o de encuestas a inmigrantes (Levitt, 2001; Kyle, 2000; Guarnizo et al., 2003; Portes, 2003). Hasta el momento se han realizado pocos estudios sistemáticos de las organizaciones involucradas en el campo transnacional, de sus orígenes y efectos. ${ }^{4}$

${ }^{4}$ Una excepción es el detallado estudio de asociaciones de oriundos (Hometown Associations) mexica- 
El presente estudio se propone realizar una contribución a fin de cubrir ese vacío del conocimiento, a partir de una encuesta sistemática aplicada a las organizaciones de inmigrantes de tres países latinoamericanos radicados en la costa este de Estados Unidos. Los datos recolectados en la encuesta nos permiten comprender mejor las fuerzas que generan y sostienen a estas organizaciones, así como poner a prueba varias hipótesis preliminares acerca de los efectos en los contextos de salida y los modos de incorporación, en los países receptores, de acuerdo al carácter del transnacionalismo inmigrante. Este trabajo se enfoca en las implicaciones del fenómeno para el desarrollo local y nacional de los países de origen. De ahí que las entrevistas con los líderes de las organizaciones, en Estados Unidos, se complementaran con visitas y entrevistas a funcionarios gubernamentales, activistas comunitarios y organizaciones que constituyen la contraparte en cada nación de origen.

Esta doble perspectiva aporta una comprensión mucho más amplia de la dinámica social y política, así como de las diferentes fuerzas que inciden en el fenómeno. El folleto de Conexión Colombia, una de las organizaciones identificadas y estudiadas, ilustra adecuadamente parte de esta dinámica:

[...] ofrecer información emotiva, útil y actualizada de modo que los colombianos en el extranjero permanezcan en contacto con su país. Por tal razón, la página web de Conexión Colombia se ha convertido en el rincón de la nostalgia (sic) en el que es posible ver los goles en el torneo local de fútbol, escuchar la música más reciente, viajar por las áreas más bellas de nuestra geografía y ubicar por todo el mundo a los restaurantes colombianos más cercanos. ${ }^{5}$

\section{DISEÑO DE LA INVESTIGACIÓN}

\section{Construcción de la base de datos}

El primer desafío al que nos enfrentamos fue realizar un inventario de las organizaciones establecidas por los grupos de inmigrantes en sus respectivas áreas de concentración. Por fortuna, existen diversas fuentes que posibilitan una enumeración casi completa, en especial de las organizaciones con lazos transnacionales. Primero, los consulados de los respectivos países generalmente disponen de listas de estas organizaciones con el propósito de mantener el contacto e influir en ellas; segundo, las confederaciones más amplias, fundadas según el criterio de naciona-

nos realizado por Manuel Orozco (2003). El estudio se basa en entrevistas a cien asociaciones y en visitas de campo a más de veinte comunidades en México que reciben apoyos de estos grupos.

${ }^{5}$ Materiales recopilados durante la entrevista de campo. Véase también la página web de la organización (www.conexioncolombia.com). 
lidad o panetnicidad (p.ej., los «hispanos») basan su actividad en identificar y unir a las organizaciones más relevantes, con lo cual aumentan su visibilidad y poder; tercero, los líderes de las organizaciones suelen estar interesados en anunciar sus metas y logros para atraer nuevos miembros y donaciones. Las organizaciones no son individuos y, a diferencia de éstos, la mayoría busca lucimiento público, al tiempo que dispone de líderes dispuestos a conceder entrevistas y proporcionar información detallada. Por estas circunstancias, el equipo de investigación pudo construir una base de datos de las organizaciones transnacionales en las principales áreas de concentración de cada grupo nacional, la cual incluye a todas las asociaciones, excepto las más fugaces o pequeñas.

\section{Nacionalidades seleccionadas}

Para el estudio se seleccionaron organizaciones de colombianos, dominicanos y mexicanos. Aun cuando estas nacionalidades de inmigrantes comparten una cultura y un lenguaje comunes, difieren por sus contextos de salida y llegada. Los colombianos constituyen un flujo inmigratorio relativamente reciente que, en la actualidad, supera el millón de personas y se concentra en la ciudad de Nueva York y en Miami. ${ }^{6}$ Los colombianos suelen ser de origen urbano, con niveles escolares más altos que otros inmigrantes latinoamericanos. Su partida ha estado motivada por la creciente violencia y las condiciones de deterioro económico y político en su país. Por ende, mientras que la mayoría de los colombianos son inmigrantes legales, hay una cifra creciente de asilados políticos. En términos de su fenotipo, los inmigrantes colombianos son blancos o mestizos claros y, por tanto, escapan, por lo general, de la discriminación que sufren los grupos no-blancos en la sociedad estadounidense (Guarnizo, Sánchez y Roach, 1999; Escobar, 2004).

Los dominicanos han llegado desde los años sesenta a la ciudad de Nueva York y a urbes más pequeñas del corredor Nueva York-Boston. Actualmente suman más de un millón y representan el grupo de inmigrantes más numeroso en Nueva York (Itzigsohn, Dore, Fernández y Vázquez, 1999). En términos de la magnitud de la población dominicana, Nueva York sólo es superado por Santo Domingo, la capital de ese país. Se trata, preponderantemente, de una migración

\footnotetext{
${ }^{6}$ El conteo del censo de Estados Unidos es de menos de la mitad de esta cifra. Con base en las cifras provenientes del gobierno colombiano y cálculos independientes de diversos especialistas, creemos que hay un serio subregistro debido a que no se cuentan a los inmigrantes sin autorización y a los asilados potenciales. En la tabla dos informamos del cálculo censal.

${ }^{7}$ El censo de Estados Unidos sitúa la cantidad de dominicanos en menos de 800 mil para el año 2000. Sin embargo, los cálculos del gobierno dominicano y de los centros de investigación especializados indican que la cantidad de inmigrantes, incluidos los que carecen de autorización, fácilmente excede al millón. Véase la tabla dos.
} 
de la clase trabajadora pero con un considerable componente de profesionistas y empresarios. Los motivos para la partida son económicos, dado que el país de origen se encuentra en paz y hay un denso tránsito entre la isla y Nueva York, por razones familiares y políticas. Los principales partidos dominicanos tienen representaciones en Nueva York y en ciudades del corredor Nueva York-Boston, en especial en Providence. El actual presidente del país, Leonel Fernández, nació y fue educado en la ciudad de Nueva York. La población de la República Dominicana es predominantemente mulata, con una capa de blancos de la clase alta que no emigran. Los migrantes dominicanos, por su fenotipo, son negros o mulatos. En Estados Unidos se les considera parte de la población negra y, por ello, se les discrimina (Portes y Guarnizo, 1991; Grasmuck y Pessar, 1991).

Los mexicanos constituyen, por mucho, el mayor grupo de inmigrantes en Estados Unidos, alcanzan más de diez millones de personas y representan, por sí solos, cerca de un tercio de la población nacida fuera de Estados Unidos. ${ }^{8}$ Históricamente, y en el momento actual, México ha funcionado, de manera efectiva, como la principal reserva de mano de obra para su poderoso vecino del norte. El fin del Programa Bracero, en 1964, condujo a la criminalización de este flujo de mano de obra y al rápido incremento en el número de inmigrantes en la categoría de indocumentados o no autorizados. Como es sabido, la inmigración mexicana tradicionalmente se ha concentrado en el suroeste y, en segundo lugar, en el medio oeste. Sus principales áreas de concentración urbano-metropolitana están en Los Ángeles, San Diego, Houston, Dallas y Chicago. Más recientemente, el flujo se ha trasladado, de manera sostenida, hacia el este, en busca de empleos agrícolas y urbanos estables en la agricultura así como en los servicios. En consecuencia, la población de origen mexicano, en estados como Georgia, se triplicó en el periodo intercensal (1990-2000) y, en la ciudad de Nueva York, se elevó desde la insignificancia, en los años ochenta, a una población estimada en 250 mil personas para el 2000 (Massey, Durand y Malone, 2002; u.s. Bureau of the Census, 2001).

En cuanto a su fenotipo, los inmigrantes mexicanos se pueden identificar por su piel más oscura y por sus rasgos mestizos o indígenas. Esta característica, además del promedio bajo en sus niveles de escolaridad y su frecuente estatus indocumentado, ha conducido a una discriminación notable por parte del gobierno de Estados Unidos y la sociedad en su conjunto. En el suroeste y el medio oeste, los mexicanos han estado confinados, tradicionalmente, a los barrios aislados y pobres, además, como los negros en otros lugares, han sido tratados como una casta inferior. Como respuesta a estas condiciones, la política étnica mexico-estadounidense se ha centrado en la lucha por superar la discriminación y el logro de un cier-

${ }^{8}$ El censo de Estados Unidos sitúa, a la población de mexicanos, en nueve millones para 2000. El gobierno mexicano, por otra parte, calcula que esa población es de doce millones, con base en el último censo mexicano. Optamos por una estimación intermedia que, con base en el probable subregistro del censo de Estados Unidos, parece conservadora (véanse Rumbaut, 2005 y Passel, 2004). 
to grado de dignidad y progreso económico para los miembros de esta minoría. En contraste, las organizaciones transnacionales mexicanas, creadas por inmigrantes rurales de primera generación, han dirigido sus esfuerzos a mejorar las condiciones materiales y políticas en sus lugares de origen (Goldring, 2002; Smith, 2005).

La tabla uno presenta una síntesis de las características de los tres grupos de inmigrantes seleccionados y de sus países de origen. Sus similitudes culturales y las diferencias estructurales aportan un telón de fondo adecuado para analizar las formas que pueden adoptar las actividades transnacionales, así como su impacto potencial en los países y comunidades de origen. Como ya se indicó, la recolección de los datos en estas organizaciones se centró en sus principales áreas de concentración, en la costa este de Estados Unidos, como sigue: colombianos, Nueva York, suburbios de Nueva Jersey y Miami; dominicanos, Nueva York, suburbios de Nueva Jersey, Boston y Providence, R.I; mexicanos, Nueva York, suburbios de Nueva Jersey, Nueva Inglaterra, Filadelfia y Carolina del Norte.

TABLA 1

Las características de los tres grupos de inmigrantes seleccionados y de sus países de origen

\begin{tabular}{|c|c|c|c|}
\hline CARACTERÍSTICAS & COLOMBIA & $\begin{array}{c}\text { REPÚBLICA } \\
\text { DOMINICANA }\end{array}$ & MÉXICO \\
\hline \multicolumn{4}{|l|}{ País de origen } \\
\hline Población (en millones) ${ }^{*}$ & 43.0 & 8.5 & 97.5 \\
\hline PIB per capita (pesos) & 2,254 & 1,862 & 4,574 \\
\hline Índice Gini de desigualdad & 0.57 & 0.47 & 0.47 \\
\hline $\begin{array}{l}\text { Porción del ingreso del } \\
\text { quintil más alto (\%) }\end{array}$ & 60.9 & 53.3 & 60.2 \\
\hline $\begin{array}{l}\text { Porción del ingreso del } \\
\text { quintil más bajo (\%) }\end{array}$ & 3.0 & 5.1 & 5.4 \\
\hline Años promedio de escolaridad"* & 8.6 & 8.2 & 8.6 \\
\hline Desempleo abierto (\%)** & 19.8 & 13.8 & 3.7 \\
\hline Empleo informal (\%)* & 46.3 & 44.0 & 44.1 \\
\hline $\begin{array}{l}\text { Hogares por debajo de } \\
\text { la línea de pobreza }(\%)\end{array}$ & 45.0 & 32.0 & 43.0 \\
\hline Capital & Bogotá & $\begin{array}{c}\text { Santo } \\
\text { Domingo }\end{array}$ & México, D.F. \\
\hline Situación política & $\begin{array}{l}\text { Democracia } \\
\text { con múltiples } \\
\text { guerras civiles }\end{array}$ & $\begin{array}{c}\text { Democracia sin } \\
\text { insurgencias } \\
\text { armadas }\end{array}$ & $\begin{array}{c}\text { Democracia } \\
\text { con rebeliones } \\
\text { locales }\end{array}$ \\
\hline
\end{tabular}

2000, aproximadamente.

** Áreas urbanas; población económicamente activa (edades 25-59). 
TABLA 1

(continuación)

\begin{tabular}{|c|c|c|c|}
\hline CARACTERÍSTICAS & COLOMBIA & $\begin{array}{c}\text { REPÚBLICA } \\
\text { DOMINICANA }\end{array}$ & MÉXICO \\
\hline \multicolumn{4}{|l|}{$\begin{array}{l}\text { Inmigrantes en } \\
\text { Estados Unidos }\end{array}$} \\
\hline Cantidad ${ }^{*}$ & 470,684 & 764,945 & $9,177,487$ \\
\hline $\begin{array}{l}\text { Porcentaje de la población } \\
\text { hispana en Estados Unidos }\end{array}$ & 1.3 & 2.1 & 58.5 \\
\hline Inmigrantes legales, 2001 & 16,730 & 21,313 & 206,426 \\
\hline $\begin{array}{l}\text { Porcentaje del total de } \\
\text { la inmigración legal }\end{array}$ & 1.6 & 2.0 & 19.4 \\
\hline $\begin{array}{l}\text { Rango en el total de } \\
\text { la inmigración legal }\end{array}$ & 16 & 14 & 1 \\
\hline $\begin{array}{l}\text { Ocupación, especialidad } \\
\text { profesional }(\%)\end{array}$ & 16.1 & 9.4 & 4.7 \\
\hline Egresados de secundaria (\%) & 72.0 & 48.1 & 29.7 \\
\hline Con título universitario (\%) & 21.8 & 9.5 & 4.2 \\
\hline $\begin{array}{l}\text { Mediana del ingreso } \\
\text { del hogar (pesos) }\end{array}$ & 43,242 & 34,311 & 36,004 \\
\hline Tipos de inmigración & $\begin{array}{l}\text { En su mayor parte } \\
\text { legal; cantidades } \\
\text { crecientes de } \\
\text { inmigrantes no } \\
\text { autorizados y } \\
\text { asilados políticos }\end{array}$ & $\begin{array}{l}\text { Legal y no } \\
\text { autorizada }\end{array}$ & $\begin{array}{l}\text { En su mayor parte no } \\
\text { autorizada, pero una } \\
\text { cantidad considerable } \\
\text { de inmigrantes legales }\end{array}$ \\
\hline $\begin{array}{l}\text { Principales ciudades } \\
\text { de destino }\end{array}$ & $\begin{array}{c}\text { Miami } \\
(15.8 \%) \\
\text { Nueva York } \\
(12.3 \%)\end{array}$ & $\begin{array}{c}\text { Nueva York } \\
(45.9 \%) \\
\text { Bergen-Passaic } \\
(5.9 \%)\end{array}$ & $\begin{array}{c}\text { Los Angeles }(16.0 \%) \\
\text { Chicago }(5.3 \%) \\
\text { Houston }(4.8 \%)\end{array}$ \\
\hline $\begin{array}{l}\text { Características de } \\
\text { la población } \\
\text { establecida en } \\
\text { Estados Unidos }\end{array}$ & $\begin{array}{c}\text { Principalmente } \\
\text { primera } \\
\text { generación }\end{array}$ & $\begin{array}{l}\text { Principalmente } \\
\text { primera } \\
\text { generación con } \\
\text { una segunda } \\
\text { generación } \\
\text { creciente }\end{array}$ & $\begin{array}{c}\text { Principalmente } \\
\text { segunda generación y } \\
\text { posterior }\end{array}$ \\
\hline
\end{tabular}

Cifras del Censo de Estados Unidos. Estimaciones de los gobiernos de los países de origen sitúan a las poblaciones de colombianos y dominicanos, residentes en Estados Unidos, en más de un millón para cada grupo y, a la población de mexicanos, por encima de los 12 millones. Fuentes: International Labor Organizations, 2003, General Labor Statistics. Comisión Económica para América Latina y el Caribe, 2002, Indicadores de Desarrollo Social. Banco Mundial, 2003, World Bank Indicators Database. Oficina del Censo de Estados Unidos, 2003, Public Use Microdata, Censo 2000. Oficina de Estadísticas de Inmigración, Department of Homeland Security, Reporte anual 2002. Naciones Unidas, World Urbanization Prospects, Revisión 2001, st/ESA/SER/A.216 Nueva York: 2002, tabla A-2. 


\section{Trabajo de campo}

Para cada nacionalidad estudiada, se seleccionaron las treinta principales organizaciones identificadas durante la elaboración del inventario, al tiempo que se entrevistó a sus líderes. Por razones presupuestales, el estudio se limitó a la costa este de Estados Unidos. En el caso de los colombianos y dominicanos, ello no constituye una limitación seria, pues sabemos que su principal área de concentración se localiza en el este; pero las organizaciones mexicanas entrevistadas apenas representan una población de reciente establecimiento, dado que la concentración más antigua y voluminosa se encuentra en las ciudades del oeste. Las organizaciones mexicanas, incluidas en la encuesta, pueden definirse como representativas de los primeros esfuerzos asociativos de esta población en estas nuevas áreas de establecimiento y, en ese carácter, es probable que sean diferentes en tamaño, edad y metas de las identificadas y estudiadas en el oeste (Goldring, 2002; Roberts, Frank y Lozano-Asencio, 1999).

La entrevista directa, de hora y media, con los líderes inmigrantes permitió recabar información sobre los orígenes organizacionales, membresía y liderazgo. Estas entrevistas fueron complementadas con reuniones con los funcionarios consulares y otros informantes familiarizados con la comunidad inmigrante, así como con varias visitas a los países de origen. En esas visitas, el equipo del proyecto estableció contacto con los departamentos gubernamentales responsables de sus respectivas poblaciones de migrantes, con entidades privadas que impulsaban relaciones con estas poblaciones y con los receptores de las donaciones y asistencia provenientes de los grupos cívicos y filantrópicos entrevistados en Estados Unidos.

El Instituto de los Mexicanos en el Exterior (IME), de la Secretaría de Relaciones Exteriores del gobierno mexicano, y el Programa Colombia nos Une, del Ministerio Colombiano de Relaciones Exteriores, constituyen ejemplos de iniciativas oficiales en este campo. Conexión Colombia ilustra una poderosa iniciativa privada que complementa los esfuerzos oficiales. Al contactar a los municipios, las iniciativas filantrópicas y las órdenes religiosas, el equipo de trabajo pudo confirmar, en campo, la existencia y los efectos de los proyectos filantrópicos promovidos por los migrantes desde el extranjero. Mientras que el impacto conjunto de esos esfuerzos es difícil de cuantificar, su innegable existencia y la atención que le prestan las agencias gubernamentales y las instituciones privadas de gran tamaño, en cada país de origen, ofrecen evidencia prima facie de su importancia.

\section{PANORAMA TEÓRICO}

\section{Definición}

El concepto de transnacionalismo fue acuñado, a principios de los años noven- 
ta, por un emprendedor grupo de antropólogos para referirse a las actividades «multisituadas» generadas por los migrantes más allá de las fronteras nacionales (Basch, Glick Schiller y Blanc-Szanton, 1994; Glick Schiller, 1999; Glick Schiller y Fouron, 1999). La variedad de estudios de caso que se suscitaron después documenta las muchas formas que estas actividades podían adoptar, al tiempo que promovía la idea de que la asimilación de los inmigrantes, según su definición convencional, era una cosa del pasado. En vez de un proceso gradual de aculturación e integración en la sociedad receptora, como se describe en la teoría clásica de la asimilación, el transnacionalismo evocaba un conjunto de imágenes de un movimiento permanente de ida y vuelta en el que los migrantes viven, simultáneamente, en dos o más sociedades y culturas, enlazándolas entre sí a través de comunidades «desterritorializadas» (Basch et al., 1994).

Las afirmaciones excesivas de esta literatura condujeron a estudiosos de la inmigración, más orientados por criterios científicos, a rechazar por completo el concepto y permanecer en el marco de la teoría convencional de la asimilación. Aparte de los numerosos pronunciamientos que esto suscitó, el concepto de transnacionalismo implicaba la dificultad adicional de haber sido aplicado, en el pasado, a varios fenómenos dispares, oscureciendo y confundiendo su significado. Ya en 1916, un reconocido intelectual, Randolph Bourne, utilizó el término en su muy citado ensayo "Transnational America», precisamente para deplorar el proceso de la asimilación de los inmigrantes que, en su visión, "genera hordas de hombres y mujeres sin un país espiritual, renegados culturales sin gusto, sin parámetros que no sean los de la multitud [...] (y) se convierten en los despojos de la vida americana» (Bourne, 1916: 90-91). ${ }^{9}$

A pesar de las dificultades, y al ver un valor heurístico en el concepto, al aplicarlo a los inmigrantes contemporáneos, otro grupo de científicos sociales se propuso definirlo más rigurosamente, de modo que pudiera ser empíricamente mensurable (Portes, Guarnizo y Landolt, 1999; Guarnizo et al., 2003). Esos investigadores adoptaron una definición de transnacionalismo para referirse a las actividades de base realizadas a través de las fronteras nacionales por los actores de la sociedad civil, independientemente de - y a veces en oposición a - las directrices y reglas oficiales. Definido de ese modo, el transnacionalismo englobaba, entre otros, los esfuerzos de los activistas de diferentes países en renglones como el ambiente, los derechos humanos y laborales, además de la democracia política (Evans, 2000; Keck y Sikkink, 1998). El transnacionalismo inmigrante constituye un subconjunto de este universo, definido por actividades regulares más allá de las fronteras nacionales de parte de personas nacidas fuera del país, como parte de sus vidas cotidianas en el extranjero.

Esta definición buscaba distinguir la participación regular en esas actividades de, por ejemplo, los envíos ocasionales de una remesa o de un viaje aislado al país de origen, acciones que los migrantes siempre han hecho y que, por sí solas, no justifican la acuñación de un nuevo término. El elemento novedoso que, ac- 
tualmente, el concepto de transnacionalismo busca capturar es la participación frecuente y duradera de los inmigrantes en la vida económica, política y cultural de sus países, lo que requiere un contacto regular y frecuente que sobrepase las fronteras nacionales. Esos contactos son posibles merced a las innovaciones en las tecnologías de transporte y comunicación, que no estaban disponibles para generaciones previas de migrantes (Levitt, 2001; Guarnizo, 2003). Por extensión, las organizaciones transnacionales son aquellas cuyas metas y actividades están parcial o totalmente ubicadas en países distintos del que residen sus miembros.

Definido así, el transnacionalismo no se asume a priori como una característica de todos los inmigrantes, ni como contrario a su asimilación. Se trata de cuestiones que se responderán en la investigación empírica. Las caracterizaciones previas de los inmigrantes como «transmigrantes» y del transnacionalismo como una alternativa a la asimilación, se basaban en la extrapolación de estudios de caso. La metodología de estos estudios mostraba la variable dependiente, al centrarse en los empresarios transnacionales o los activistas políticos, y excluía a los inmigrantes que no participaban en esas acciones (Portes, 2003).

La definición más restringida del concepto, adoptada por estudios recientes, plantea investigar la magnitud real del fenómeno, entre diferentes grupos de inmigrantes, con una tipología que pretende distinguir 1) las actividades internacionales conducidas por los gobiernos y otras instituciones de sede nacional; 2) las iniciativas multinacionales de las agencias de la Organización de las Naciones Unidas, las iglesias globales y los actores corporativos que operan en múltiples países; y 3) el mundo transnacional de las empresas y las iniciativas de los actores de la sociedad civil, incluidos los inmigrantes. El propósito de esta tipología es delimitar y diferenciar, claramente, el alcance de este último concepto respecto a otros fenómenos que también interactúan a través de las fronteras, pero que son conducidos por actores más institucionalizados y bastante más poderosos. Si se deja fuera de esta distinción, el concepto de transnacionalismo se convierte en una noción demasiado amplia que carece de valor heurístico.

\section{Participación de \\ los Estado-nación}

Esta tipología tiene una utilidad adicional, al enfatizar las posibles interacciones e influencia recíproca de los tres tipos de actividades transfronterizas, según se distinguen líneas atrás. Resulta que los gobiernos — especialmente los de las naciones de origen - no han sido indiferentes a las iniciativas de sus expatriados y, cada vez más, buscan influir en ellas. Son comprensibles las razones de la participación gubernamental: el creciente volumen de remesas de los emigrados; la inversión de los expatriados en viviendas, terrenos y empresas en su país; así como las actividades cívicas y filantrópicas que trascienden las fronteras. En conjunto, estas actividades 
han crecido hasta lograr importancia «estructural» para el desarrollo de las comunidades locales e, incluso, naciones (Guarnizo, 2003; Vertovec, 2004).

Los gobiernos de los países de origen han reaccionado promoviendo leyes que permiten, a los migrantes, conservar su nacionalidad aún cuando se naturalicen en otro país. Quienes siguen como ciudadanos de su país han logrado votar e, incluso, postularse para cargos públicos mientras viven en otro país. Los consulados han recibido instrucciones de adoptar una postura más activa hacia las comunidades de inmigrantes y han comenzado a ofrecer una cantidad importante de servicios a sus compatriotas, incluyendo representación legal, asistencia médica, tarjetas de identificación, enseñanza del inglés y del idioma propio del país de origen (Escobar, 2003, 2004; Smith, 2003; Itzigsohn et al., 1999).

Mediante estas iniciativas, los gobiernos buscan preservar la lealtad de sus expatriados e incrementar y canalizar sus remesas, inversiones y contribuciones filantrópicas. La importancia de estas iniciativas oficiales puede verse en el hecho de que casi todos los gobiernos de los países de origen las han asumido: desde México a Turquía; de Colombia a Eritrea, y de la República Dominicana a Filipinas (Portes, 2003). En términos de la tipología de tres categorías, esbozada arriba, esto significa que las actividades internacionales, que asumen los diplomáticos y los funcionarios del gobierno de estos países, se orientan cada vez más a promover y guiar las iniciativas transnacionales de sus comunidades emigradas.

El aumento de esos programas oficiales ha alimentado la impresión de que el transnacionalismo inmigrante no es más que un reflejo y una reacción a dichas iniciativas. Nada más lejos de la verdad: toda la evidencia empírica indica que las actividades económicas, políticas y socioculturales, que vinculan a las comunidades de expatriados con sus países de origen, surgieron por iniciativa de los migrantes mismos, y que los gobiernos se subieron al carro, únicamente, cuando se evidenció su importancia y potencial económico (Landolt, 2001; Guarnizo et al., 1999; Smith, 2005). Sin embargo, la presencia cada vez más activa de los gobiernos de los países de origen, en el campo transnacional, no deja de influir la forma y las metas adoptadas por las iniciativas de las bases. Según el alcance y los recursos materiales asignados por los gobiernos, así como los propósitos para los que son utilizados, las organizaciones inmigrantes pueden aceptar y adoptar la línea oficial, seguir independientes de ésta o resistirla activamente como una interferencia no deseada. Regresaremos más adelante a estas diferentes interacciones entre las actividades internacionales y transnacionales.

\section{Controversias e hipótesis}

Waldinger y Fitzgerald (2004) han señalado que, realmente, no hay nada nuevo en el concepto de transnacionalismo. Los inmigrantes siempre se han comprometido con sus países y comunidades de origen, por lo que es posible encontrar mu- 
chos ejemplos de lo que hoy se llama transnacionalismo en la literatura sobre los inmigrantes europeos en América a principios del siglo xx. Efectivamente, existen múltiples ejemplos históricos de actividades transfronterizas de base. No obstante, hasta que se acuñó y refinó el concepto de transnacionalismo, el carácter común y la importancia de este fenómeno permanecieron poco claros. Por ejemplo, el vínculo teórico, entre el activismo político de los emigrantes rusos o polacos y las actividades comerciales de la diáspora china, no podía haberse percibido sino existiera una lente teórica que los conectara y señalara su convergencia.

En este sentido, Waldinger y Fitzgerald avanzan hacia lo que Merton (1968) identificó hace ya mucho tiempo como la «falacia de la adumbración», la cual consiste en negar el valor de un descubrimiento científico al señalar las instancias previas de éste. Robert Smith aterriza el argumento al hacer notar que: «Si la vida transnacional existió en el pasado pero no era vista como tal, entonces la lente transnacional realiza el trabajo analítico de proporcionar una forma de ver que no podía percibirse antes» (Smith, 2003: 725).

En concordancia con el enunciado de Smith, el concepto ha contribuido a que surja una fértil literatura de investigación, así como a la formulación de ideas e hipótesis subsidiarias que no existían previamente en el campo de la inmigración. Algunas de estas hipótesis se relacionan con la participación individual en las empresas y actividades transnacionales, al tiempo que otras tratan el carácter de estas organizaciones. La única encuesta cuantitativa realizada en este campo hasta el momento, el Comparative Immigrant Entrepreneurship Project (CIEP), descubrió que la educación estaba asociada, positivamente, con la participación en actividades transnacionales - económicas, políticas y culturales-al igual que con el estatus laboral y civil. Los hombres casados tienen una mayor probabilidad de participar, mientras que, con un mayor tiempo de residencia en el extranjero, de hecho se incrementa la probabilidad del transnacionalismo (Portes et al., 2002; Guarnizo et al., 2003).

Los hallazgos del estudio del CIEP indican que, al contrario de la historia convencional de asimilación, el mantenimiento y cultivo de lazos con la nación de origen no decae con el tiempo transcurrido desde la inmigración. Estas actividades son más comunes entre los mejor establecidos, con mayor escolaridad y mayores ingresos. Es decir, las personas que disponen de los recursos necesarios pueden involucrase en empresas complejas y demandantes que trascienden las fronteras, no así quienes han llegado más recientemente y que son más pobres. A la luz de estos hallazgos, planteamos la hipótesis de que la asimilación en el país receptor y la participación en las actividades transnacionales no necesariamente se oponen entre sí, como suponían antes ambas escuelas (Guarnizo et al., 2003; Portes et al., 2002; Portes, 2003).

El estudio del CIEP también encontró diferencias significativas en la participación transnacional, según los contextos de salida y llegada de diferentes grupos de inmigrantes: quienes provienen de áreas rurales, ya fueran inmigrantes 
o refugiados, tienden a formar comités cívicos de oriundos sin tintes políticos para el apoyo de las localidades que dejaron; los inmigrantes de orígenes más urbanos, por lo común, participan más en la política y en la vida cultural de sus países, en especial si los partidos políticos, iglesias e instituciones culturales buscan mantener una presencia activa entre los expatriados (Itzigsohn y Saucedo, 2002; Guarnizo et al., 2003). Los programas iniciados por los gobiernos del país de origen pueden, también, desempeñar un papel significativo, en especial si trascienden los llamados simbólicos y aportan ayudas reales para los migrantes en el extranjero. En esos casos, la dirección y las metas adoptadas por las actividades transnacionales de las bases pueden ser influidas, fuertemente, por las directrices oficiales (Escobar, 2003; Smith, 2003). Con base en estos hallazgos, planteamos la hipótesis de que las diferencias en el contexto sociopolítico de salida y el carácter participativo de los gobiernos del país de origen influirán, significativamente, la forma y las actividades de las organizaciones creadas por los inmigrantes.

Finalmente, los contextos de llegada, asimismo, pueden afectar el inicio de las actividades, según el nivel de discriminación sobre los recién llegados. Por ejemplo, cuando un grupo de inmigrantes, por razones de escaso capital humano o por estereotipos raciales, es discriminado, existen muchas razones para que se unifique y adopte una postura defensiva ante el país receptor, apelando a los símbolos de orgullo cultural transportados desde su origen. Cuando estas condiciones no se presentan, las iniciativas transnacionales pueden tornarse más individualizadas y las organizaciones, cuando existen, pueden adoptar formas de «clase media» reconocibles y aceptables en la sociedad dominante. Ejemplos de este modo de transnacionalismo alternativo lo constituyen el Club de Leones, el Club Kiwanis, la Asociación de Damas de la Caridad. Esta tercera hipótesis, fundamentada en resultados empíricos previos, se pone a prueba junto a las otras a partir de los datos del nuevo estudio.

\section{RESULTADOS}

\section{Orígenes, tipos y estructura de las organizaciones transnacionales}

La Fundación Global para la Democracia y el Desarrollo (FUnGLODE) es una organización privada no gubernamental fundada por Leonel Fernández, presidente de la República Dominicana, antes de su reelección. La Fundación ha establecido una «alianza estratégica» con el Instituto de Estudios Dominicanos de la Universidad de la Ciudad de Nueva York (CunY, por sus siglas en inglés) a fin de realizar congresos, formar grupos de trabajo conjuntos y explorar otras rutas para dar más voz a los dominicanos, en Estados Unidos, sobre asuntos del país. Este tipo de actividad opera a un alto nivel de formalización y, en términos de nuestra tipología, 
podría llamársele más correctamente «internacional» que «transnacional». Hay algo de este último elemento, no obstante, por la gran cantidad de inmigrantes dominicanos que toman parte en esta alianza y porque a Fernández, su fundador, se le ocurrió la idea cuando era un inmigrante en Nueva York. ${ }^{9}$

En el otro extremo de la formalización se sitúa la Fundación de los Cañafisteros de Bani, de Boston, una asociación de base creada por los inmigrantes dominicanos de Nueva Inglaterra para ayudar a su pueblo y provincia natales (Bani). Un comité que sirve de contraparte en Bani recibe y distribuye los donativos regulares que se hacen en dinero y especie. Hasta el momento, los migrantes cañafisteros han enviado una ambulancia y una carroza fúnebre a su pueblo, equipado con uniformes al equipo local de béisbol, comprado un generador de electricidad para la clínica, adquirido varias clases de equipo médico y escolar, así como creado un fondo para dar 100 dólares al mes a las familias necesitadas en Cañafistol. Literalmente, han transformado el pueblo, el que depende cada vez más de la lealtad y generosidad de sus emigrados para resolver varias necesidades que no son atendidas por el gobierno nacional. ${ }^{10}$

Estos ejemplos sirven adecuadamente para mostrar nuestros datos, ya que éstos enfatizan la notable gama de actividades transnacionales, incluso entre los provenientes del mismo país. La tabla dos presenta un perfil inicial de nuestro muestreo de organizaciones de inmigrantes. El tipo predominante es el de aquellas que se autodefinen como «entidades cívicas» y que impulsan una agenda de alcance nacional. En la tabla tres aparecen ejemplos que incluyen a organizaciones creadas por los migrantes, como el Club de Leones Colombianos de Miami y la Asociación de Provincias Dominicanas de Nueva York. El ejemplo mexicano es de alcance regional, una asociación de migrantes, en Carolina del Norte, que surgió bajo el patrocinio del gobierno de Guanajuato, su estado de origen.

En segundo lugar de importancia están los clubes de oriundos (hometown committees), cuyo alcance es principalmente local. La tabla tres proporciona ejemplos, incluido el mencionado de los cañafisteros de Boston y un conjunto de clubes bien organizados, constituidos por mexicanos de Xochilhuehuetlan, un pueblo del estado de Guerrero. A continuación se sitúan las agencias sociales que proporcionan servicios de salud, educación y otros a los inmigrantes en Estados Unidos, pero que también están comprometidas en proyectos en su país de origen. Es común que estas organizaciones estén mejor financiadas, dado que sus presupuestos incluyen fondos para servicios sociales aportados por los gobiernos de las localidades, condados y estados en la Unión Americana.

Las organizaciones políticas transnacionales representan una pequeña mi-

\footnotetext{
${ }^{9}$ Entrevistas de campo realizadas por el equipo de investigación en Nueva York y República Dominicana, en 2004.

${ }^{10}$ Entrevistas de campo, 2004.
} 
noría de esta muestra y, entre los inmigrantes mexicanos, no están representadas en absoluto pues, para ellos, su centro de interés está, primordialmente, en sus comunidades de origen. Entre los dominicanos, la representación de los partidos políticos es bastante importante. Como puede verse en la tabla tres, el Partido Revolucionario Dominicano (PRD) de Nueva York afirma que tiene 23 mil afiliados en el área metropolitana y, el Partido de Liberación Dominicano (PLD) de Massachussets, mil quinientos. Aún cuando estas cifras probablemente sean exageradas, muestran el significado de la política partidista para este grupo específico de inmigrantes.

TABLA 2

Perfil de las organizaciones

transnacionales de inmigrantes

\begin{tabular}{|c|c|c|}
\hline VARIABLE & VALORES & $\%$ \\
\hline \multirow[t]{3}{*}{ Origen nacional: } & Colombianas & 36.0 \\
\hline & Dominicanas & 35.0 \\
\hline & Mexicanas & 29.0 \\
\hline \multirow[t]{4}{*}{ Ubicación: } & Nueva York/Nueva Jersey & 54.0 \\
\hline & Miami & 20.2 \\
\hline & Filadelfia & 4.5 \\
\hline & Otras & 21.3 \\
\hline \multirow[t]{10}{*}{ Tipo de organización: } & Cívica & 40.4 \\
\hline & $\begin{array}{l}\text { Comité de oriundos } \\
\text { (Hometown Committee) }\end{array}$ & 18.0 \\
\hline & Agencia social & 12.4 \\
\hline & Cultural & 7.9 \\
\hline & Política & 6.7 \\
\hline & Profesional & 4.6 \\
\hline & Religiosa & 3.4 \\
\hline & Educativa & 2.2 \\
\hline & Deportiva & 2.2 \\
\hline & Económica & 2.2 \\
\hline \multirow{3}{*}{$\begin{array}{l}\text { Alcance de los proyectos en } \\
\text { el país de origen: }\end{array}$} & Local & 26.0 \\
\hline & Regional & 13.0 \\
\hline & Nacional & 61.0 \\
\hline
\end{tabular}


TABLA 2

(continuación)

\begin{tabular}{|c|c|c|}
\hline VARIABLE & VALORES & $\%$ \\
\hline \multirow{5}{*}{$\begin{array}{l}\text { Centro de la actividad } \\
\text { en el país de origen: }\end{array}$} & Educación/Escuelas & 53.9 \\
\hline & Salud & 40.4 \\
\hline & Niños/Ancianos & 30.3 \\
\hline & Iglesia & 13.5 \\
\hline & Partidos políticos & 7.9 \\
\hline \multirow[t]{2}{*}{ Estatus legal: } & $\begin{array}{l}\text { Organización formal } \\
\text { sin fines de lucro }\end{array}$ & 45.0 \\
\hline & Informal/Otro & 55.0 \\
\hline \multirow{4}{*}{$\begin{array}{l}\text { Frecuencia de los eventos cívicos } \\
\text { patrocinados por la organización: }\end{array}$} & Ocasionalmente & 24.4 \\
\hline & Anualmente & 36.6 \\
\hline & Varias veces al año & 26.8 \\
\hline & Una vez al mes o más & 12.2 \\
\hline \multirow[t]{3}{*}{$\begin{array}{l}\text { Frecuencia de los festivales patrocinados } \\
\text { por la organización: }\end{array}$} & Ocasionalmente & 19.0 \\
\hline & Anualmente & 52.4 \\
\hline & Varias veces al año & 28.6 \\
\hline \multirow[t]{6}{*}{ Fuentes de financiamiento:" } & Cuotas de los miembros & 59.0 \\
\hline & Compañías privadas & 60.3 \\
\hline & Iglesias & 12.8 \\
\hline & Fundaciones & 9.2 \\
\hline & $\begin{array}{l}\text { Gobierno del } \\
\text { país de origen }\end{array}$ & 9.1 \\
\hline & $\begin{array}{l}\text { Partidos políticos } \\
\text { del país de origen }\end{array}$ & 2.6 \\
\hline \multicolumn{3}{|c|}{$\mathrm{N}=90$} \\
\hline
\end{tabular}

"Los porcentajes no suman cien porque las organizaciones pueden estar involucradas en múltiples proyectos.

"* Los porcentajes no suman cien debido a que las organizaciones pueden tener múltiples fuentes de financiamiento. 
TABLA 3

Ejemplos de organizaciones transnacionales

\begin{tabular}{|c|c|c|c|c|}
\hline TIPO & NOMBRE & NACIONALIDAD & UBICACIÓN & $\begin{array}{c}\text { CANTIDAD } \\
\text { DE MIEMBROS }\end{array}$ \\
\hline \multirow[t]{3}{*}{ Cívico: } & $\begin{array}{l}\text { Club Colombiano de } \\
\text { Leones en Miami }\end{array}$ & Colombiana & Miami & 32 \\
\hline & $\begin{array}{c}\text { Asociación de Provincias } \\
\text { Dominicanas }\end{array}$ & Dominicana & $\begin{array}{l}\text { Nueva York/ } \\
\text { Nueva Jersey }\end{array}$ & 48 \\
\hline & Casa Guanajuato & Mexicana & $\begin{array}{l}\text { Carrboro, } \\
\text { North Carolina }\end{array}$ & 26 \\
\hline \multirow[t]{3}{*}{$\begin{array}{l}\text { Comité de } \\
\text { oriundos: }\end{array}$} & Fundación Quimbaya & Colombiana & $\begin{array}{l}\text { Nueva York/ } \\
\text { Nueva Jersey }\end{array}$ & 28 \\
\hline & Cañafisteros de Bani en Boston & Dominicana & Boston & 25 \\
\hline & $\begin{array}{c}\text { San Miguel Comitipla } \\
\text { (Xochihuehuetlan, Guerrero) }\end{array}$ & Mexicana & $\begin{array}{l}\text { Nueva York/ } \\
\text { Nueva Jersey }\end{array}$ & 260 \\
\hline \multirow[t]{3}{*}{$\begin{array}{l}\text { Agencia } \\
\text { social: }\end{array}$} & $\begin{array}{l}\text { Centro comunitario } \\
\text { Las Américas }\end{array}$ & Colombiana & Miami & 95 \\
\hline & $\begin{array}{c}\text { Hermanas Mirabal y Red de } \\
\text { Atención Familiar }\end{array}$ & Dominicana & $\begin{array}{l}\text { Nueva York/ } \\
\text { Nueva Jersey }\end{array}$ & 20 \\
\hline & $\begin{array}{c}\text { Casa Mexicana de Nueva Jersey- } \\
\text { Corporativo de desarrollo }\end{array}$ & Mexicana & Nueva Jersey & 20 \\
\hline \multirow[t]{2}{*}{ Religioso: } & Comité del Divino Niño & Colombiana & $\begin{array}{l}\text { Nueva York/ } \\
\text { Nueva Jersey }\end{array}$ & 11 \\
\hline & Domingo dominicano & Dominicana & $\begin{array}{l}\text { Nueva York/ } \\
\text { Nueva Jersey }\end{array}$ & 9 \\
\hline \multirow[t]{3}{*}{ Político: } & $\begin{array}{l}\text { Comité de acción política } \\
\text { Colombiano-Americana }\end{array}$ & Colombiana & Miami & 25 \\
\hline & $\begin{array}{l}\text { Partido Revolucionario } \\
\text { Dominicano Party (PRD) }\end{array}$ & Dominicana & $\begin{array}{l}\text { Nueva York/ } \\
\text { Nueva Jersey }\end{array}$ & 23,000 \\
\hline & $\begin{array}{c}\text { Partido de Liberación } \\
\text { Dominicana (PLD) }\end{array}$ & Dominicana & Boston & 1,500 \\
\hline
\end{tabular}

Fuente: Comparative Immigrant Transnational Organization Project (CiOP). 
La tabla tres muestra que la mayor parte de estas organizaciones opera de manera informal, aunque el $45 \%$ se han registrado como entidades formales sin fines de lucro. Independientemente de su estatus, la principal preocupación filantrópica, de la mayoría de estos grupos, tiene que ver con la educación y la salud en sus comunidades y países de origen, seguidas por el cuidado de los niños y los ancianos. Los datos revelan una amplia diferencia en los recursos disponibles de las organizaciones para poner en práctica estas iniciativas, pues van desde unos cuantos miles de dólares hasta cerca del millón. Como se mencionó antes, las agencias sociales son las organizaciones con mayores fondos y, también, son las más frecuentes en la muestra de organizaciones dominicanas. Esto explica la diferencia tan notable en el promedio de los recursos monetarios entre las organizaciones de las tres nacionalidades, como se aprecia en la tabla cuatro.

El hecho de que esta diferencia se deba tan sólo a unas cuantas organizaciones bien financiadas, se evidencia cuando examinamos la mediana de los recursos financieros en vez del promedio. La mediana está influida por las frecuencias y no por los valores extremos, por ende, la diferencia entre las nacionalidades en este indicador se hace mucho más pequeña. Aún así, las organizaciones dominicanas se conservan como las mejor financiadas, mientras las mexicanas se quedan muy atrás. La misma historia se repite cuando consideramos los presupuestos mensuales o la cantidad de empleados asalariados. Cuatro quintas partes de las organizaciones inmigrantes transnacionales no tienen cuadros administrativos pagados, pero el 25\% de las dominicanas emplean a cinco trabajadores asalariados o más. Ninguna organización de las otras dos nacionalidades se encuentra en esta categoría.

En su mayoría se trata de organizaciones de voluntarios con un promedio de 35 miembros regulares. La cifra se dilata hacia arriba, hasta llegar a casi mil entre los dominicanos. El hecho de que las organizaciones de los partidos políticos sean escasas en número, se refleja en la mediana que descuenta los valores extremos. La diferencia en el tamaño de la membresía se hace mucho menor, aunque las organizaciones dominicanas conservan alguna ventaja. Como en las cifras para los recursos monetarios, los datos respecto a la membresía (tanto la regular como la ocasional) indican una amplia dispersión, con organizaciones que van desde un puñado de activistas comprometidos hasta los cientos de miembros.

\section{Características de la membresía}

Pedimos a los líderes de cada organización seleccionada que nos informaran sobre las características de sus miembros regulares. Estos datos son importantes porque inciden en hipótesis opuestas respecto a los determinantes del transnacionalismo. Como ya vimos, una perspectiva ortodoxa de asimilación vería, a tales actividades, como propias de inmigrantes más recientes que todavía no han cortado sus lazos con sus países y culturas de origen, a la vez que están más dispuestos 
TABLA 4

Características cuantitativas de las organizaciones de inmigrantes

\begin{tabular}{|c|c|c|c|c|}
\hline VARIABLE & COLOMBIANAS & DOMINICANAS & MEXICANAS & TOTAL \\
\hline Número promedio de miembros & 44 & 939 & 69 & 356 \\
\hline Mediana del número de miembros & 25 & 34 & 23 & 26 \\
\hline $\begin{array}{l}\text { Número promedio de } \\
\text { miembros ocasionales }\end{array}$ & 65 & 1,061 & 144 & 492 \\
\hline $\begin{array}{l}\text { Mediana del número de } \\
\text { miembros ocasionales }\end{array}$ & 23 & 20 & 25 & 20 \\
\hline $\begin{array}{c}\text { Promedio de } \\
\text { los fondos monetarios }\end{array}$ & 24,056 & 695,737 & 24,470 & 247,493 \\
\hline $\begin{array}{c}\text { Mediana de } \\
\text { los fondos monetarios }\end{array}$ & 20,000 & 24,000 & 5,000 & 20,000 \\
\hline \multicolumn{5}{|c|}{ GASTOS MENSUALES } \\
\hline Sin gastos $(\%)$ & 46.7 & 10.0 & 60.0 & 37.7 \\
\hline Menos de $1,000(\%)$ & 33.3 & 23.3 & 20.0 & 25.9 \\
\hline Menos de 5,000 (\%) & 16.7 & 43.3 & 16.0 & 24.8 \\
\hline 5,000 o más (\%) & 3.3 & 23.4 & 4.0 & 10.6 \\
\hline \multicolumn{5}{|c|}{ EMPLEADOS ASALARIADOS } \\
\hline Ninguno (\%) & 87.1 & 70.0 & 82.6 & 79.8 \\
\hline Menos de 5 (\%) & 12.9 & 3.3 & 17.4 & 10.7 \\
\hline Menos de 10 (\%) & 0.0 & 16.7 & 0.0 & 6.0 \\
\hline 10 ó más (\%) & 0.0 & 10.0 & 0.0 & 3.5 \\
\hline $\mathrm{N}$ & 31 & 30 & 29 & 90 \\
\hline
\end{tabular}

Fuente: Comparative Immigrant Transnational Organization Project (CIOP). 
a ayudar a quienes se han quedado. A medida que transcurre el tiempo, estos lazos habrían de debilitarse, cuando los inmigrantes logran establecerse mejor, pueden dominar el inglés al hablar y están más cómodos en sus nuevos ambientes, entonces tendrían que abandonar, gradualmente, la participación activa en sus países de origen (Alba y Nee, 2003; Gordon, 1964; Warner y Srole, 1945). Por el contrario, los hallazgos del estudio del CIEP, sintetizados previamente, indican que son los inmigrantes de más edad, con mayor escolaridad y mejor establecidos quienes se inclinan a participar en estas empresas. La explicación es que se trata de individuos con la información, la seguridad y los recursos de tiempo y dinero para dedicarlos a estas iniciativas (Portes et al., 2002; Guarnizo et al., 2003).

Las organizaciones incluidas en este proyecto tienen una membresía que se estima en 9,040 inmigrantes, ó 32,040, si se toman en cuenta los afiliados al PRD de Nueva York. La tabla cinco presenta datos relevantes acerca de sus características sociodemográficas promedio. Los resultados apoyan, de manera consistente, la hipótesis de que las organizaciones transnacionales están apoyadas por inmigrantes de más edad, con mayor escolaridad y mejor establecidos. Alrededor de la mitad de los miembros regulares de las organizaciones tiene 40 años de edad o más y, al menos, un grado académico o superior, en contraste con una quinta parte, o casi, menor de 30 años o que alcanza un grado menor a la secundaria (High School). La excepción la constituyen las organizaciones de mexicanos, que atrajeron una proporción mayor de personas jóvenes y que tienen tanto a personas de baja escolaridad como de alta escolaridad. Este hallazgo es coherente con el bien conocido promedio bajo en capital humano, así como la juventud de la población de inmigrantes mexicanos en su conjunto (Cornelius, 1998; Lopez y Stanton-Salazar, 2001; Massey et al., 2002).

Las cifras referentes al estatus laboral describen una historia similar respecto a la doble proporción de los profesionistas y empresarios frente a los trabajadores manuales, entre los miembros de las organizaciones. Una vez más, la excepción la constituyen las asociaciones mexicanas, pues la proporción de participantes con bajo y alto estatus es más o menos la misma. No obstante, las cifras que contradicen, de manera más decidida, la hipótesis ortodoxa de la asimilación refieren al conocimiento del idioma inglés, el estatus legal y la duración de la residencia en Estados Unidos. Como se muestra en la tabla cinco, cerca del 60\% de los inmigrantes que apoyan, activamente, las organizaciones transnacionales hablan inglés bien o muy bien, en contraposición con tan sólo el 12\% que lo hablan mal. El patrón es claro entre las nacionalidades, incluidos los mexicanos.

De manera similar, cerca del $70 \%$ de los miembros de estas organizaciones han vivido en Estados Unidos por 10 años o más y, la mitad de ellos, ya son ciudadanos de Estados Unidos. Sólo una décima parte está constituida por personas relativamente recién llegadas o que se encuentran en el país sin una visa legal. Una excepción parcial es, nuevamente, la de las organizaciones de mexicanos que reciben, aproximadamente, una cuarta parte de su membresía regular de entre los 
TABLA 5

Características de los miembros de las organizaciones transnacionales

\begin{tabular}{|c|c|c|c|c|}
\hline & COLOMBIANAS & DOMINICANAS & MEXICANAS & TOTAL \\
\hline \multicolumn{5}{|c|}{ EDAD } \\
\hline 30 años o menos (\%) & 12.1 & 11.1 & 24.8 & 15.2 \\
\hline 40 años o más (\%) & 53.2 & 53.8 & 33.6 & 48.3 \\
\hline \multicolumn{5}{|c|}{ ESCOLARIDAD } \\
\hline Menor a secundaria (\%) & 7.4 & 29.7 & 28.7 & 20.9 \\
\hline $\begin{array}{l}\text { Título universitario o } \\
\text { superior (\%) }\end{array}$ & 52.3 & 50.5 & 27.0 & 45.7 \\
\hline \multicolumn{5}{|c|}{ OCUPACIÓN } \\
\hline Trabajador manual (\%) & 18.0 & 26.4 & 40.1 & 26.6 \\
\hline $\begin{array}{c}\text { Profesional/ } \\
\text { Propietario negocio (\%) }\end{array}$ & 49.8 & 61.5 & 36.0 & 50.3 \\
\hline \multicolumn{5}{|c|}{ CONOCIMIENTO DEL INGLÉS } \\
\hline Muy poco (\%) & 11.9 & 18.7 & 5.0 & 12.4 \\
\hline Bien o muy bien (\%) & 64.2 & 49.7 & 60.9 & 58.5 \\
\hline \multicolumn{5}{|c|}{ ESTATUS LEGAL } \\
\hline No tiene visa de entrada (\%) & 6.3 & 3.5 & 27.9 & 10.7 \\
\hline $\begin{array}{c}\text { Ciudadano de } \\
\text { Estados Unidos (\%) }\end{array}$ & 56.3 & 48.5 & 38.4 & 49.1 \\
\hline \multicolumn{5}{|c|}{$\begin{array}{l}\text { TIEMPO DE RESIDENCIA EN } \\
\text { ESTADOS UNIDOS }\end{array}$} \\
\hline Menos de 5 años (\%) & 10.1 & 5.8 & 10.4 & 8.7 \\
\hline Diez años o más(\%) & 68.9 & 66.8 & 69.5 & 69.3 \\
\hline \multicolumn{5}{|c|}{$\begin{array}{l}\text { PROMEDIO DE VIAJES AL PAÍS DE ORIGEN } \\
\text { POR ASUNTOS DE LA ORGANIZACIÓN }\end{array}$} \\
\hline Nunca o rara vez (\%) & 6.7 & 3.6 & 30.0 & 11.5 \\
\hline $\begin{array}{l}\text { Al menos tres viajes } \\
\text { al año }(\%)\end{array}$ & 40.0 & 35.7 & 20.0 & 33.3 \\
\hline
\end{tabular}

Fuente: Comparative Immigrant Transnational Organizations Project (CIOP). 
inmigrantes sin papeles; pero, incluso entre ellos, los ciudadanos naturalizados sobrepasan a los indocumentados.

A partir de estos datos concluimos que la motivación para participar en las actividades cívicas, filantrópicas, políticas y de otro tipo en el país de origen, entre los inmigrantes latinoamericanos, se encuentra, principalmente, entre los miembros de mayor escolaridad y estatus más alto en sus respectivas comunidades y, de ellos, quienes tienen periodos más prolongados de residencia en Estados Unidos y un estatus legal seguro. Aparentemente, el proceso que está en juego es aquel en que los inmigrantes recientes se concentran en generar un nicho en el país receptor, en vez de ocuparse en la organización colectiva. Estas iniciativas surgen y comienzan a influir a las localidades y países de origen sólo después de que las etapas iniciales de la adaptación se han culminado con éxito. Dado que la mitad de los participantes en estas organizaciones ya son ciudadanos estadounidenses, y que el 70\% ha estado en el país durante diez años o más, concluimos que la asimilación y el transnacionalismo no se oponen, sino que, de hecho, pueden ocurrir de manera simultánea. Ni siquiera las organizaciones mexicanas contradicen esta conclusión, dado que, mientras que muchos miembros de los clubes de oriundos siguen sin documentos, la gran mayoría de los participantes ha permanecido en el país por un tiempo significativo.

\section{Determinantes de las características de las organizaciones}

Con los datos disponibles es posible investigar, con mayor detalle, las características y orígenes de las organizaciones transnacionales. Este análisis incide, directamente, en las hipótesis referentes a los contextos de salida y de incorporación en el surgimiento de estas organizaciones. Las variables dependientes para este análisis son el tipo de organización, ya sea que haya logrado un estatus formal o no, las causas de su creación, las fuentes de su financiamiento y el alcance de su acción. Utilizamos, como predictores, la nacionalidad de las organizaciones y, como controles, el tamaño de su membresía así como los recursos financieros y características de sus miembros: edad, escolaridad, estatus de su visa y duración de la residencia en Estados Unidos. Con excepción de la nacionalidad, que sirve como variable proxy para las características de origen y recepción de cada grupo de inmigrantes, no se asume ninguna causalidad en lo que se refiere a los hallazgos de estas variables de control.

La tabla seis presenta los resultados para una regresión logística multinomial del tipo de organización y una regresión logística binomial respecto a si la organización está incorporada formalmente, como carente de fines de lucro, o si opera de manera informal. Sólo se incluyen los tres principales tipos de organización: cívica/cultural, clubes de oriundos y las agencias de servicio social. 
TABLA 6

Ejemplos de organizaciones transnacionales

\begin{tabular}{|c|c|c|c|c|c|c|c|c|}
\hline $\begin{array}{c}\text { CARACTERÍSTICAS DE LAS } \\
\text { ORGANIZACIONES }\end{array}$ & \multicolumn{6}{|c|}{ TIPO DE ORGANIZACIÓN } & & \\
\hline \multirow[t]{2}{*}{ PREDICTORES } & \multicolumn{2}{|c|}{ CÍVICO/CULTURAL $^{1}$} & \multicolumn{2}{|c|}{ CLUBES DE ORIUNDOS } & \multicolumn{2}{|c|}{$\begin{array}{c}\text { AGENCIAS DE } \\
\text { SERVICIO SOCIAL }\end{array}$} & \multicolumn{2}{|c|}{$\begin{array}{l}\text { FORMAL SIN } \\
\text { FINES DE LUCRO }\end{array}$} \\
\hline & I & II & I & II & I & $\mathrm{II}^{3}$ & I & II \\
\hline \multicolumn{9}{|c|}{ NACIONALIDAD ${ }^{4}$} \\
\hline Colombiana & - & - & - & - & - & & - & - \\
\hline Mexicana & - & - & $\begin{array}{l}3.83^{* *} \\
(2.8)\end{array}$ & $\begin{array}{l}4.49^{*} \\
(2.3)\end{array}$ & $\begin{array}{l}4.10^{\circ} \\
(2.6)\end{array}$ & $\begin{array}{l}7.51^{*} \\
(2.1)\end{array}$ & $\begin{array}{c}-2.26^{*} \\
(3.2)\end{array}$ & $\begin{array}{c}-4.07^{* * *} \\
(3.5)\end{array}$ \\
\hline \multicolumn{9}{|c|}{ UBICACIÓN ${ }^{5}$} \\
\hline $\begin{array}{l}\text { Nueva York/ } \\
\text { Nueva Jersey }\end{array}$ & - & & - & - & - & - & - & - \\
\hline Filadelfia & - & - & - & - & - & - & - & - \\
\hline \multicolumn{9}{|c|}{ CARACTERÍSTICAS ORGANIZACIONES } \\
\hline $\begin{array}{l}\text { Recursos financieros } \\
\text { (logarítmico) }\end{array}$ & - & - & - & & $\begin{array}{l}1.25^{\circ} \\
(3 / 0)\end{array}$ & $\begin{array}{l}2.24 \\
(2.0)\end{array}$ & - & - \\
\hline $\begin{array}{c}\text { Número de miembros } \\
\text { (logarítmico) }\end{array}$ & - & $\begin{array}{c}-0.635^{\circ} \\
(2.2)\end{array}$ & - & & $\begin{array}{c}-0.738^{\#} \\
(1.8)\end{array}$ & $\begin{array}{l}-1.48^{\#} \\
(1.9)\end{array}$ & - & - \\
\hline \multicolumn{9}{|c|}{ CARACTERÍSTICAS MIEMBROS } \\
\hline $\begin{array}{l}\text { Porcentaje con menos } \\
\text { de } 20 \text { años de edad }\end{array}$ & & & & - & & & & $\begin{array}{c}-0.027^{\circ} \\
(2.2)\end{array}$ \\
\hline $\begin{array}{c}\text { Porcentaje de } 40 \text { años } \\
\text { de edad o más }\end{array}$ & & & & - & & & & - \\
\hline $\begin{array}{c}\text { Porcentaje de } \\
\text { escolaridad menor a } \\
\text { secundaria }\end{array}$ & & & & - & & & & - \\
\hline $\begin{array}{c}\text { Porcentaje con } \\
\text { escolaridad posterior al } \\
\text { título universitario }\end{array}$ & & & & $\begin{array}{c}-0.071 \\
(2.3)\end{array}$ & & & & - \\
\hline $\begin{array}{c}\text { Porcentaje sin visa de } \\
\text { entrada legal }\end{array}$ & & & & - & & & & $.052^{*}(2.5)$ \\
\hline $\begin{array}{l}\text { Porcentaje de } \\
\text { ciudadanos de } \\
\text { Estados Unidos }\end{array}$ & & & & - & & & & - \\
\hline $\begin{array}{l}\text { Porcentaje de } \\
\text { residencia en Estados } \\
\text { Unidos menor a } 5 \text { años }\end{array}$ & & & & - & & & & - \\
\hline $\begin{array}{c}\text { Porcentaje de } 10 \text { años } \\
\text { o más de residencia en } \\
\text { Estados Unidos }\end{array}$ & & & & - & & & & - \\
\hline Constante & 2.10 & 3.94 & -3.77 & -1.01 & -10.92 & -24.36 & 1.60 & 2.05 \\
\hline $\mathrm{N}$ & 89 & & 89 & & 89 & & 89 & \\
\hline Pseudo $\mathrm{R}^{2}$ & $.234^{\ldots * *}$ & $.450^{\cdots}$ & $.234^{* *}$ & $.450^{\ldots * *}$ & $.234^{\ldots *}$ & $.450^{\cdots}$ & $.124^{*}$ & $.257^{\circ}$ \\
\hline
\end{tabular}

${ }^{1}$ Coeficientes logísticos multinomiales. Razones-z entre paréntesis. No se incluyen los coeficientes que no son significativos en el nivel de 0.10 .

${ }^{2}$ Coeficientes logísticos binomiales. Razones-z entre paréntesis. No se incluyen los coeficientes que no son significativos en el nivel de 0.10.

${ }^{3}$ Las iteraciones de probabilidad máxima no coinciden debido a los limitados grados de libertad.

${ }^{4}$ La categoría de referencia es "Dominicano".

${ }^{5}$ La categoría de referencia es «a algún otro lugar».

\# $p<.10 / /$ " $p<0.05 / /$ "* $p<0.01 / /$ "** $p<0.001$ 
Estas regresiones están encapsuladas y el primer modelo incluye las características de la organización: ubicación, origen nacional y tamaño de la membresía (logarítmica),además de la magnitud de los recursos financieros (logarítimica); la segunda ecuación añade las características de los miembros. Sólo los coeficientes significativos, en el nivel de 0.10 o menores, se presentan aquí. Con una muestra de tan sólo 90 casos, los coeficientes en este nivel de significado pueden ser razonablemente interpretados como importantes.

Las organizaciones cívico/culturales constituyen, por mucho, el principal tipo y no están bien representadas por este conjunto de predictores. Los orígenes nacionales no tienen un efecto significativo ni tampoco la ubicación geográfica o las características de sus miembros. Estos resultados indican que las organizaciones cívico/culturales constituyen la forma normativa del transnacionalismo inmigrante y que surgen independientemente de los orígenes del grupo, cómo se le recibe o dónde se concentra. El único resultado significativo es el logaritmo del tamaño de la membresía, que muestra que, respecto a otros tipos de organizaciones - como las agencias de servicios sociales o las ramas de los partidos políticos-, las entidades cívico/culturales tienden a ser más pequeñas.

Por otro lado, los hallazgos refuerzan la conclusión de que los clubes de oriundos son la forma normativa del transnacionalismo entre los migrantes mexicanos. Respecto a la categoría de referencia (dominicanos), la probabilidad de que un club de oriundos sea mexicano es de 46 a uno. El hecho de que estos clubes sean creados primordialmente por inmigrantes de orígenes modestos, se refleja en el efecto negativo de la educación superior: mientras más alta es la proporción de egresados de la universidad entre sus miembros, menos probable es que esa organización transnacional sea un club de oriundos.

Las agencias de servicios sociales también son significativamente menos comunes entre los inmigrantes colombianos y dominicanos, en comparación con los mexicanos. La probabilidad de que una agencia de servicio social participe en actividades transnacionales entre los mexicanos, en el primer modelo, es de 60 a uno respecto a la nacionalidad de referencia. Por otro lado, el hecho de que se trata de las organizaciones mejor dotadas financieramente se refleja en el coeficiente positivo y significativo de los recursos financieros. No es un efecto causal, sino un reflejo directo del hecho de que estas organizaciones tienen una mayor probabilidad de recibir fondos provenientes de las ciudades y estados en que se ubican.

La probabilidad de que una organización transnacional se formalice como carente de fines de lucro, en vez de que opere informalmente, está afectada por el origen nacional. Como reflejo de su carácter de base y su creación por migrantes de antecedentes más modestos, las asociaciones de mexicanos tienden a operar informalmente, su probabilidad neta de lograr el estatus formal, en comparación con las creadas por los dominicanos, es menos de uno a diez. Cuando se controla la variable de nacionalidad, las organizaciones con una mayor proporción de miembros jóvenes y aquellos sin papeles tienden a operar de manera más formal. Este resultado 
TABLA 7

Ejemplos de organizaciones transnacionales

\begin{tabular}{|c|c|c|c|c|c|c|c|c|}
\hline $\begin{array}{l}\text { ORÍGENES Y ALCANCE DE LAS } \\
\text { ORGANIZACIONES }\end{array}$ & \multicolumn{6}{|c|}{ ORÍGENES ${ }^{1}$} & \multirow{2}{*}{\multicolumn{2}{|c|}{$\begin{array}{c}\text { ALCANCE }^{2} \\
\text { EN TODO EL PAÍS }\end{array}$}} \\
\hline PREDICTORES & \multicolumn{2}{|c|}{ GRUPO DE AMIGOS } & \multicolumn{2}{|c|}{ FONDOS DE GOBIERNO } & \multicolumn{2}{|c|}{$\begin{array}{l}\text { DESASTRES } \\
\text { NATURALES }\end{array}$} & & \\
\hline & I & II & I & II & I & $\mathrm{II}^{3}$ & I & II \\
\hline \multicolumn{9}{|c|}{ NACIONALIDAD ${ }^{4}$} \\
\hline Colombiana & - & - & - & - & $\begin{array}{c}24.778^{* *} \\
(2.7)\end{array}$ & & - & - \\
\hline Mexicana & - & - & $\begin{array}{l}22.901^{* * *} \\
(7.2)\end{array}$ & $\begin{array}{c}45.036^{\circ} \\
(3.3)\end{array}$ & - & & - & - \\
\hline \multicolumn{9}{|c|}{ UBICACIÓN $^{5}$} \\
\hline Nueva York/Nueva Jersey & - & - & - & - & - & & - & - \\
\hline Filadelfia & - & - & - & - & - & & - & - \\
\hline \multicolumn{9}{|c|}{ CARACTERÍSTICAS ORGANIZACIONES } \\
\hline $\begin{array}{l}\text { Recursos financieros } \\
\text { (logarítmico) }\end{array}$ & - & - & - & - & - & & - & - \\
\hline $\begin{array}{l}\text { Número de miembros } \\
\text { (logarítmico) }\end{array}$ & - & - & - & - & - & & - & - \\
\hline \multicolumn{9}{|c|}{ CARACTERÍSTICAS DE LOS MIEMBROS } \\
\hline $\begin{array}{c}\text { Porcentaje de menos de } 20 \\
\text { años de edad }\end{array}$ & & - & - & - & & & & - \\
\hline $\begin{array}{l}\text { Porcentaje de } 40 \text { años de } \\
\text { edad o más }\end{array}$ & & - & - & $\begin{array}{c}0.279^{\#} \\
(1.7)\end{array}$ & & & & $\begin{array}{c}0.126^{\#} \\
(1.7)\end{array}$ \\
\hline $\begin{array}{l}\text { Porcentaje de escolaridad } \\
\text { menor a secundaria }\end{array}$ & & - & - & - & & & & - \\
\hline $\begin{array}{l}\text { Porcentaje con título } \\
\text { universitario o más }\end{array}$ & & - & - & - & & & & $\begin{array}{c}0.033^{\circ} \\
(2.5)\end{array}$ \\
\hline $\begin{array}{l}\text { Porcentaje sin visa de } \\
\text { entrada legal }\end{array}$ & & - & - & - & & & & - \\
\hline $\begin{array}{l}\text { Porcentaje de ciudadanos } \\
\text { de Estados Unidos }\end{array}$ & & - & - & - & & & & - \\
\hline $\begin{array}{c}\text { Porcentaje de menos de } \\
5 \text { años de residencia en } \\
\text { Estados Unidos }\end{array}$ & & - & & & & & & - \\
\hline $\begin{array}{l}\text { Porcentaje } 10 \text { años o } \\
\text { más de residencia en } \\
\text { Estados Unidos }\end{array}$ & & $\begin{array}{r}0.034^{\circ} \\
(2.1)\end{array}$ & & & & & & - \\
\hline Constante & 0.409 & -0.193 & 18.343 & 59.493 & -34.633 & & -0.717 & -4.77 \\
\hline $\mathrm{N}$ & 89 & & 89 & & & & 89 & \\
\hline Pseudo $\mathrm{R}^{2}$ & $0.293^{* * *}$ & $0.530^{\circ \cdots}$ & $0.293^{* * *}$ & $0.530^{* * *}$ & $0.293^{\cdots}$ & & 0.068 & $0.316^{* * *}$ \\
\hline
\end{tabular}

${ }^{1}$ Coeficientes logísticos multinomiales. Razones-z entre paréntesis. Los coeficientes que no son significativos en el nivel de 0.10 fueron excluidos.

${ }^{2}$ Coeficientes logísticos binomiales. Razones-z entre paréntesis. Los coeficientes que no son significativos en el nivel de 0.10 fueron excluidos.

${ }^{3}$ Las iteraciones de probabilidad máxima no concuerdan debido a la escasez de casos.

${ }^{4}$ La categoría de referencia es "Dominicana».

${ }^{5} \mathrm{La}$ categoría de referencia es «en otro lugar».

${ }^{*} p<0.10 / /{ }^{*} p<0.05 / /{ }^{* *} p<0.01 / /{ }^{* * *} p<0.001$ 
inesperado se explica en parte como un efecto residual después de controlar, para el origen mexicano, la mayor fuente de inmigrantes jóvenes e indocumentados.

Es posible obtener otra información útil a partir de las regresiones adicionales, con base en las razones por las cuales fue creada cada organización, así como su alcance de acción en su país de origen. Los datos relevantes provienen de regresiones multinomiales de la primera variable y una regresión binomial de la gama de la acción, en donde "en todo el país» es codificado como uno y «local» como cero. Los resultados se presentan en la tabla siete. Las asociaciones transnacionales fundadas por "grupos de amigos» no se diferencian por nacionalidad o por la mayoría de las otras características colectivas e individuales. Esto refleja el hecho de que esos esfuerzos espontáneos se dan entre todos los tipos de inmigrantes, independientemente de los orígenes nacionales, la edad o la escolaridad y, las organizaciones creadas de ese modo, no son significativamente menores o más pobres que las que se derivan de fuentes más institucionales. El único resultado adicional que resalta es que los inmigrantes con periodos más prolongados de residencia tienden a ser menos comunes entre los miembros de estas asociaciones, como se muestra en el modelo de la columna iI. Se podría argumentar que se trata de un resultado de la preferencia que muestran los inmigrantes establecidos por las iniciativas más formales e institucionalizadas.

Como han apuntado los resultados descriptivos anteriores, las organizaciones creadas a iniciativa de los gobiernos del país de origen tienden a ser excepcionales, pero las que han surgido de este modo se concentran en tan sólo un grupo nacional. Como se muestra en la tabla siete, las organizaciones mexicanas tienen una mayor probabilidad de situarse en esta categoría. El coeficiente respectivo es muy fuerte, lo que hace que sea mucho más probable que una organización transnacional mexicana sea creada por iniciativa del gobierno que en el caso de los dominicanos (la categoría de referencia). ${ }^{11}$ Este resultado refleja la postura activa del gobierno mexicano en lo que se refiere a su gran población de expatriados, un tema que se discute con mayor detalle en la siguiente sección.

Las organizaciones fundadas como respuesta a los desastres naturales son, significativamente, más comunes entre los colombianos. El coeficiente relativo una vez más es bastante fuerte, pues indica que hay una mayor probabilidad de que las organizaciones colombianas hayan surgido de este modo. Este resultado refleja los orígenes más urbanos de los colombianos y sus patrones de establecimiento más individualistas, lo que puede requerir que surjan emergencias nacionales o regionales para hacerlos sensibles a la acción colectiva (Guarnizo y Díaz, 1999). ${ }^{12}$

\footnotetext{
${ }^{11}$ Las probabilidades correspondientes son más altas de lo creíble, como resultado de un número limitado de casos y la consecuente dificultad de la máxima probabilidad de la rutina iterativa para estimar los modelos. Por tal razón, los resultados deben interpretarse con cuidado, como cifras preliminares.

${ }^{12}$ Sin embargo, no puede descartarse la posibilidad de que una frecuencia relativamente mayor de esas emergencias en Colombia, en los años recientes, pueda también (en parte) explicar este resultado.
} 
Finalmente, la tabla siete responde a la pregunta de qué factores están asociados con el activismo transnacional de alcance nacional, en contraposición con uno exclusivamente local o regional. El modelo binomial en la columna II indica que el alcance nacional de la acción está asociado, primordialmente, con una membresía universitaria y de mayor edad. Las organizaciones que reúnen a inmigrantes más jóvenes y las de orígenes más modernos tienden a centrarse, principalmente, en los temas locales. Las organizaciones mexicanas están sobre-representadas entre aquellas que tienen una membresía de baja escolaridad, de modo que este resultado es, esencialmente, una reformulación de su dominio entre los clubes de oriundos.

En general, estos resultados revelan patrones diferenciados entre las comunidades de inmigrantes en cuanto a los tipos de organizaciones que éstas crean, sus motivaciones para hacerlo y el alcance que se proponen en la acción. Estos patrones corresponden, adecuadamente, a las diferencias bien conocidas en la composición del capital humano de estos flujos de inmigrantes y a sus contextos de salida e incorporación: de estos resultados surge una clara diferencia en las formas de transnacionalismo adoptadas por los inmigrantes mexicanos — centrada en el bienestar de comunidades que, en su mayoría, son rurales y con una alta dosis de intervención gubernamental - respecto a las adoptadas por dominicanos y colombianos, cuyas organizaciones tienden a ser más altas en su alcance, más formalizadas y, con mayor frecuencia, son creadas por iniciativas espontáneas de las bases para responder a desastres y otras emergencias nacionales. El impacto neto de estas diferentes formas de transnacionalismo, en los países de origen, se examina a continuación.

\section{IMPACTO EN}

LAS NACIONES DE ORIGEN

Como se mencionó antes, nuestro proyecto complementó la encuesta a las organizaciones transnacionales en Estados Unidos con visitas a los países de origen, con el objeto de evaluar, en campo, esta forma de activismo. Dicha parte del estudio fue cualitativa, pero el saldo de las entrevistas no deja duda en cuanto al significado, real y potencial, de las iniciativas transnacionales. Dado que es imposible presentar, en detalle, la información recolectada en estas entrevistas, a continuación sintetizamos los resultados obtenidos en cada país y los ilustramos con ejemplos representativos.

\section{Colombia}

Como mencionamos antes, la principal iniciativa en este campo, de parte del Estado colombiano, es el programa Colombia nos une, establecido por el Ministerio de 
Asuntos Exteriores en 2003 con apoyo directo del actual presidente de la república, Álvaro Uribe. El programa ha organizado una serie de seminarios acerca de la migración internacional en Colombia, patrocinado un estudio empírico de las remesas y reunido al personal consular de Colombia, en Estados Unidos y Europa, para explorar formas de adoptar una postura más activa hacia las referentes comunidades de expatriados. Las limitaciones presupuestales han evitado que este programa ofrezca ayuda real a los inmigrantes o contacte, directamente, a sus miembros. Este último papel lo ha asumido la organización de patrocinio privado Conexión Colombia, que utiliza su página web y su material de propaganda para solicitar donativos a los expatriados y canalizarlos hacia causas filantrópicas en el país.

$\mathrm{Ni}$ Colombia nos une ni Conexión Colombia han aportado, hasta el momento, un canal importante que vincule a las organizaciones de migrantes con su país de origen; en cambio se ha centrado, principalmente, en contactar a los expatriados de manera individual, a través de medios como los sitios de Internet. La figura uno presenta ejemplos de la forma en que se establecen estos contactos. Como el grupo de inmigrantes con mayor escolaridad y origen urbano, de entre los tres grupos estudiados, los colombianos han creado formas de transnacionalismo similares a las bien conocidas instituciones filantrópicas del mundo desarrollado. Éstas se ejemplifican por el surgimiento de los Clubes de Leones y Kiwanis en Estados Unidos, cuyos líderes viajan a Colombia para establecer acuerdos formales para asistencia programática, en coordinación con las instancias caritativas locales.

De tal forma que los Leones colombianos de Miami y Nueva York han donado equipo, materiales y dineros a los orfanatos en los pueblos de Quindío y Valle, al tiempo que han aportado asistencia directa tras los desastres naturales en estas regiones, por medio de sus clubes que funcionan como contrapartes en ciudades como Armenia y Cali. El Club Kiwanis de Miami ha hecho algo similar al apoyar, entre otros, un asilo y una escuela para niños discapacitados en la ciudad de Calarcá, Departamento de Quindío.

Los lazos religiosos se ejemplifican por los proyectos de las Hermanas Vicentinas de la Caridad, en Bogotá, y su conexión con una parroquia de Nueva Jersey. Un conmovedor caso es el de un grupo de inmigrantes colombianos, en Nueva York y Nueva Jersey, que contribuyó a crear, apoyar con constancia y visitar con frecuencia una escuela-refugio para niños discapacitados en su pueblo La Tebaida, Quindío. El director de la escuela dijo lo siguiente, acerca de los Hijos de Tebaida en Nueva York:

Han estado aquí veinte años y nos han ayudado desde que comenzamos. Primero nos dieron un donativo de 900 mil pesos que, para ese entonces, era mucho dinero. Hicimos mucho con ese dinero. Después, los hijos han apoyado muchos programas: almuerzos para los niños, ventiladores eléctricos y muchas otras cosas. El piso y el techo de este edificio fueron construidos con otro donativo. Yo les mando cartas diciéndoles lo que necesitamos. A veces mando tres al año. 
FIGURA 1

Conexiones transnacionales de las organizaciones de inmigrantes colombianos

\begin{tabular}{|c|c|c|c|c|c|}
\hline \multicolumn{3}{|c|}{ ESTADOS UNIDOS } & \multicolumn{3}{|c|}{ COLOMBIA } \\
\hline Tipo & Lugar & Nombre & Nombre & $\begin{array}{c}\text { Lugar } \\
\text { (ciudad y } \\
\text { departamento) }\end{array}$ & Programas \\
\hline $\begin{array}{l}\text { Cívico/ } \\
\text { Filantrópico }\end{array}$ & $\begin{array}{l}\text { Morristown, } \\
\text { NJ }\end{array}$ & $\begin{array}{l}\text { Montenegro } \\
\text { Cívico } \\
\text { Internacional } \\
\quad(\mathrm{MCI})\end{array}$ & $\begin{array}{l}\text { Junta de } \\
\text { Montenegro } \\
\text { Cívico } \\
\text { Internacional }\end{array}$ & $\begin{array}{l}\text { Montenegro, } \\
\text { Quindío }\end{array}$ & $\begin{array}{l}\text { Becas universitarias, apoyo } \\
\text { a la iglesia y al gobierno } \\
\text { municipal } \\
\text { Asistencia directa a las } \\
\text { familias pobres y a niños en el } \\
\text { pueblo y sus alrededores } \\
\text { Materiales médicos y para } \\
\text { bomberos, posteriores a } \\
\text { desastres naturales }\end{array}$ \\
\hline $\begin{array}{c}\text { Cívico/ } \\
\text { Filantrópico }\end{array}$ & Miami, FL & $\begin{array}{l}\text { Misión por } \\
\text { Colombia } \\
\text { (MINICOL) }\end{array}$ & $\rightarrow \begin{array}{c}\text { Asociación } \\
\text { Sonríe } \\
\text { Colombia } \\
\text { (sonCOL) }\end{array}$ & $\begin{array}{l}\text { La Victoria, } \\
\text { Valle }\end{array}$ & $\begin{array}{l}\text { Orfanato y escuela para niños } \\
\text { pobres y discapacitados } \\
\text { Cursos de entrenamiento } \\
\text { artesanal para estudiantes } \\
\text { pobres } \\
\text { Programa de patrocinio directo } \\
\text { para niños }\end{array}$ \\
\hline $\begin{array}{l}\text { Cívico/ } \\
\text { Filantrópico }\end{array}$ & Miami, FL & $\begin{array}{l}\text { Leones } \\
\text { colombianos } \\
\text { Club de Miami }\end{array}$ & $\begin{array}{c}\text { Club de } \\
\text { Leones de } \\
\text { Armenia }\end{array}$ & $\begin{array}{l}\text { Armenia, } \\
\text { Quindío }\end{array}$ & $\begin{array}{l}\text { Orfanato, Juan xxIII } \\
\text { Compra de una ambulancia } \\
\text { para el pueblo } \\
\text { «Brigadas de salud» en barrios } \\
\text { pobres } \\
\text { Centro de cuidado infantil en } \\
\text { barrio pobre } \\
\text { Comida y materiales para } \\
\text { bomberos y de tipo médico, } \\
\text { posteriores a terremoto } \\
\text { Programa para adolescentes } \\
\text { embarazadas }\end{array}$ \\
\hline Filantrópico & Miami, FL & $\begin{array}{l}\text { Club de } \\
\text { mujeres } \\
\text { colombianas } \\
\text { voluntarias }\end{array}$ & $\nearrow^{\text {DAVIDA }}$ & $\begin{array}{l}\text { La Tebaida, } \\
\text { Quindío }\end{array}$ & $\begin{array}{l}\text { Asilo de grandes dimensiones, } \\
\text { escuela y clínica para niños y } \\
\text { adolescentes discapacitados en } \\
\text { la región }\end{array}$ \\
\hline Filantrópico & Connecticut & $\begin{array}{l}\text { Demos la } \\
\text { Mano a } \\
\text { Colombia }\end{array}$ & 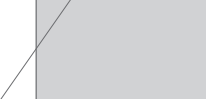 & & $\begin{array}{l}\text { Asistencia en salud para las } \\
\text { víctimas del terremoto en la } \\
\text { región }\end{array}$ \\
\hline $\begin{array}{c}\text { Cívico/ } \\
\text { Filantrópico }\end{array}$ & $\begin{array}{l}\text { Nueva York/ } \\
\text { Nueva Jersey }\end{array}$ & $\begin{array}{c}\text { Los Hijos de La } \\
\text { Tebaida }\end{array}$ & & & \\
\hline Religioso & Passaic, NJ & $\begin{array}{l}\text { Fundación del } \\
\text { Divino Niño }\end{array}$ & $\rightarrow \begin{array}{c}\text { Convento de } \\
\text { las Hermanas } \\
\text { Vicentinas de } \\
\text { la Caridad }\end{array}$ & Bogotá y Tunja & $\begin{array}{l}\text { Orfanato para niños } \\
\text { abandonados, Tunja } \\
\text { Refugio y rehabilitación de } \\
\text { personas sin vivienda y de } \\
\text { farmacodependientes, Bogotá } \\
\text { Asistencia y entrenamiento } \\
\text { vocacional para familias } \\
\text { desplazadas por la guerra civil, } \\
\text { Bogotá }\end{array}$ \\
\hline
\end{tabular}


Siempre estoy pidiendo porque también siento que ellos son parte de nosotros y nosotros somos parte de ellos. ${ }^{13}$

En concordancia con nuestras expectativas, el transnacionalismo colombiano ejemplifica la forma que adopta este fenómeno entre los inmigrantes urbanos con un nivel de escolaridad relativamente alto, cuyas actividades filantrópicas se realizan individualmente o a través de organizaciones seculares y religiosas, las cuales son familiares y compatibles con las que operan en el mundo desarrollado. Surgen a partir de esfuerzos de las bases, con frecuencia como respuesta a las emergencias o simple pobreza en los lugares de origen.

\section{Dominicanos}

Al igual que Colombia, el Estado dominicano ha aprobado leyes que conceden a sus emigrantes el derecho a nacionalizarse en el extranjero sin perder su ciudadanía dominicana y el derecho a votar en las elecciones nacionales. Los partidos políticos y las asociaciones que participan en las actividades políticas han sido de lo más visibles y exitosas para atraer una gran cantidad de migrantes. El acento que ponen, las organizaciones de inmigrantes dominicanos, se moldea en parte por la naturaleza política de las primeras oleadas de la migración dominicana. Incluso, si se diera una migración posterior por razones económicas, el carácter político de los primeros emigrados ha continuado configurando el desarrollo asociativo de esta colectividad (Escobar, 2006). Leonel Fernández, reelecto para la Presidencia, ha dado prioridad al desarrollo de relaciones con la comunidad de expatriados, al nombrar un secretario para los dominicanos en el extranjero y diseñar un programa (que se pondrá en práctica) para integrarlos mejor en la vida social y política del país. ${ }^{14}$

Las iniciativas de los inmigrantes en este campo han adoptado dos formas: asistencia en casos de desastres naturales y asociaciones cívicas de oriundos. La mayor agencia dominicana en Nueva York, Alianza Dominicana, se preocupa principalmente de proporcionar servicios sociales a los inmigrantes, pero también ha estado activa para ofrecer asistencia a los municipios y provincias cuando surgen emergencias. La inundación provocada por un río en el pueblo de Jimaní, en 2004, durante la cual más de 700 personas perdieron la vida, fue la ocasión más reciente de las actividades caritativas de la Alianza en la isla. Las iglesias locales, por lo común, son utilizadas como conducto para la asistencia, con el objeto de evitar la corrupción oficial.

\footnotetext{
${ }^{13}$ Entrevistas de campo realizadas por el equipo de investigación en Nueva York y Colombia, 2004.

${ }^{14}$ Entrevistas de campo en República Dominicana, 2004.
} 
FIGURA 2

Conexiones internacionales y transnacionales de las organizaciones dominicanas

\begin{tabular}{|c|c|c|c|c|c|c|c|}
\hline \multicolumn{3}{|c|}{ ESTADOS UNIDOS } & \multicolumn{5}{|c|}{ REPÚBLICA DOMINICANA } \\
\hline Tipo & Ubicación & Nombre & & Nombre & Ubicación & Tipo & Programa \\
\hline $\begin{array}{l}\text { Educación e } \\
\text { investigación }\end{array}$ & $\begin{array}{l}\text { Nueva } \\
\text { York }\end{array}$ & $\begin{array}{c}\text { Instituto } \\
\text { de Estudios } \\
\text { Dominicanos, } \\
\text { CUNY }\end{array}$ & & $\begin{array}{l}\text { Fundación } \\
\text { Global para la } \\
\text { Educación y } \\
\text { el Desarrollo } \\
\text { (FUNGLODE) }\end{array}$ & $\begin{array}{c}\text { Santo } \\
\text { Domingo }\end{array}$ & $\begin{array}{c}\text { Educativo } \\
\text { Cívico }\end{array}$ & $\begin{array}{l}\text { Congresos } \\
\text { Proyectos man- } \\
\text { comunados } \\
\text { y comités de } \\
\text { control } \\
\text { Promoción de } \\
\text { la participación } \\
\text { cívica y política } \\
\text { por los expatria- } \\
\text { dos en el país de } \\
\text { origen }\end{array}$ \\
\hline Político & $\begin{array}{c}\text { Nueva } \\
\text { York }\end{array}$ & $\begin{array}{c}\text { Partido Re- } \\
\text { volucionario } \\
\text { Dominicano, } \\
\text { rama local }\end{array}$ & & $\begin{array}{l}\text { Partido Revolu- } \\
\text { cionario Domi- } \\
\text { nicano (PRD), } \\
\text { Departamento } \\
\text { para los domi- } \\
\text { nicanos en el } \\
\text { extranjero }\end{array}$ & $\begin{array}{c}\text { Santo } \\
\text { Domingo }\end{array}$ & Político & $\begin{array}{l}\text { Recolección } \\
\text { de fondos para } \\
\text { candidatos del } \\
\text { partido } \\
\text { Movilización y } \\
\text { campañas para } \\
\text { el voto en el } \\
\text { extranjero }\end{array}$ \\
\hline Político & $\begin{array}{c}\text { Boston, } \\
\text { MA }\end{array}$ & $\begin{array}{l}\text { Partido de } \\
\text { Liberación } \\
\text { Dominicana, } \\
\text { rama local }\end{array}$ & & $\begin{array}{l}\text { Partido de } \\
\text { Liberación Do- } \\
\text { minicana (PLD) } \\
\text { Departamento } \\
\text { de Asuntos } \\
\text { Exteriores }\end{array}$ & $\begin{array}{c}\text { Santo } \\
\text { Domingo }\end{array}$ & Político & $\begin{array}{l}\text { Recolección } \\
\text { de fondos para } \\
\text { candidatos del } \\
\text { partido } \\
\text { Movilización y } \\
\text { campañas para } \\
\text { el voto en el } \\
\text { extranjero }\end{array}$ \\
\hline $\begin{array}{l}\text { Agencia } \\
\text { Social }\end{array}$ & $\begin{array}{c}\text { Nueva } \\
\text { York }\end{array}$ & $\begin{array}{c}\text { Alianza } \\
\text { Dominicana }\end{array}$ & $\rightarrow$ & $\begin{array}{c}\text { Consejo } \\
\text { Nacional de } \\
\text { Emergencia } \\
\text { Parroquias } \\
\text { locales y ONG's }\end{array}$ & $\begin{array}{c}\text { Santo } \\
\text { Domingo } \\
\text { Pueblos y } \\
\text { provincias } \\
\text { afectados }\end{array}$ & $\begin{array}{l}\text { Agencia de } \\
\text { gobierno } \\
\text { Religioso } \\
\text { Filantrópico }\end{array}$ & $\begin{array}{l}\text { Asistencia del } \\
\text { gobierno des- } \\
\text { pués de desas- } \\
\text { tres naturales } \\
\text { Proyectos de } \\
\text { salud y educa- } \\
\text { tivos }\end{array}$ \\
\hline $\begin{array}{c}\text { Agencia de } \\
\text { salud/ } \\
\text { social }\end{array}$ & $\begin{array}{c}\text { Bronx, } \\
\text { NY }\end{array}$ & $\begin{array}{l}\text { Hermanas } \\
\text { Mirabal, Red } \\
\text { de atención } \\
\text { familiar }\end{array}$ & & $\begin{array}{c}\text { Comité } \\
\text { Coordinador } \\
\text { de Mujeres del } \\
\text { Cibao }\end{array}$ & $\begin{array}{l}\text { Santiago } \\
\text { de los } \\
\text { Caballeros }\end{array}$ & $\begin{array}{c}\text { Cívico } \\
\text { Servicios de } \\
\text { salud }\end{array}$ & $\begin{array}{l}\text { Promoción de } \\
\text { los derechos de } \\
\text { la mujer } \\
\text { Campañas en } \\
\text { contra de la } \\
\text { violencia domés- } \\
\text { tica } \\
\text { Servicios de } \\
\text { salud infantil }\end{array}$ \\
\hline Iglesia & $\begin{array}{l}\text { Washing- } \\
\text { ton Heig- } \\
\text { hts, NY }\end{array}$ & $\begin{array}{l}\text { Ministerio } \\
\text { San Romero - } \\
\text { (Episcopal) }\end{array}$ & & $\begin{array}{c}\text { Villa } \\
\text { Altagracia } \\
\text { Centro de } \\
\text { Mujeres }\end{array}$ & $\begin{array}{c}\text { Villa } \\
\text { Altagracia }\end{array}$ & $\begin{array}{l}\text { Cívico } \\
\text { Política }\end{array}$ & $\begin{array}{l}\text { Defensa de los } \\
\text { derechos de la } \\
\text { mujer } \\
\text { Campañas en } \\
\text { contra de la } \\
\text { violencia domés- } \\
\text { tica } \\
\text { Educación de las } \\
\text { autoridades }\end{array}$ \\
\hline
\end{tabular}


Las asociaciones de oriundos, fundadas por los propios expatriados, han adoptado formas y metas similares a las colombianas. Un ejemplo notable es el de los Cañafisteros de Bani en Boston, organización que fue creada por un grupo representativo de su pueblo y ha aportado todo tipo de equipamiento y programas de asistencia para los pobres y ancianos. Un ejemplo paralelo es la Asociación de Jimanenses de Massachussets (ASOJIMA), que también ha dado a su pueblo una ambulancia, una carroza funeraria, una clínica, útiles escolares y generosa asistencia financiera tras la inundación de 2004. El apoyo a los grupos de mujeres, que luchan por los derechos femeninos y en contra de la violencia doméstica en las ciudades del interior, ha provenido de las iglesias en Nueva York y de agencias de inmigrantes como la Familia de las Hermanas Mirabal y la Red de Atención al Infante del Bronx. La figura dos presenta una síntesis de estos lazos internacionales y transnacionales.

\section{Mexicanos}

El caso del transnacionalismo de los migrantes mexicanos es diferente de los otros en varios aspectos centrales. La población de inmigrantes mexicanos no sólo es de mayor magnitud que la de todos los grupos de latinoamericanos juntos, sino que, además, es predominantemente de origen rural. Las lealtades tradicionales a los lugares de nacimiento se traducen en una proliferación de asociaciones cívicas de oriundos, misma que las hace mucho más numerosas y duraderas que las establecidas por otros grupos de inmigrantes. Un ejemplo de la diferencia es que, mientras que las asociaciones colombianas y dominicanas dependen de las rifas, bailes y acontecimientos similares para recolectar fondos, los inmigrantes mexicanos, por lo común, contribuyen de manera regular a sus asociaciones como una forma de continuar con sus cargos tradicionales hacia su terruño.

Es igualmente importante la fuerte y activa presencia del Estado en el campo transnacional. Como se señaló anteriormente, se trata de una instancia en la cual las actividades internacionales del gobierno interactúan con las iniciativas transnacionales de los inmigrantes. Varios estados mexicanos, comenzando por el bien estudiado caso de Zacatecas (Goldring, 2002; González Gutiérrez, 1999), se han movilizado para crear federaciones de clubes de oriundos y promover nuevas asociaciones. Los gobernantes, estatales y municipales, así como legisladores de Zacatecas viajan, con frecuencia, a Los Ángeles para estrechar lazos con los líderes de las federaciones de clubes de inmigrantes, quienes, a su vez, visitan con regularidad a su estado. Zacatecas ha sido un importante apoyo para el programa Dos por Uno (actualmente Tres por Uno) por el cual cada dólar donado por las organizaciones de migrantes, para obras públicas en México, es equiparado con las contribuciones de los gobiernos federal y estatal en México (Smith, 2003; Goldring, 2002).

Otros estados de alta emigración, como Jalisco y Michoacán, han adopta- 
do el modelo zacatecano y promovieron la creación de federaciones en centros de importante migración de mexicanos, como Los Ángeles, Chicago y Houston, durante la década de los noventa. Este ejemplo ha sido secundado, recientemente, por los migrantes de estados en que la migración no era una actividad tradicional (en la mayoría de los casos, con la ayuda de los consulados mexicanos y los gobiernos de los estados). En la costa este, en donde la población inmigrante de origen mexicano proviene en su mayoría de Puebla, las organizaciones comunitarias recibieron un fuerte apoyo del consulado en Nueva York y del gobierno de su estado, durante los noventa, para el establecimiento de la Casa Puebla. Desde 1994, el estado de Guanajuato ha apoyado el establecimiento de 45 Casas Guanajuato en catorce estados de la Unión Americana, incluidas las cinco abiertas recientemente en la costa este (Escobar, 2006).

En este ámbito, ha sido todavía más importante la presencia del gobierno federal mexicano, a través del fondo de coinversión donde participan los migrantes, p. ej., el Programa Tres por Uno, inaugurado en 2002; la creación de plazas comunitarias en varias ciudades de Estados Unidos, que ofrecen servicios de biblioteca, información y cursos de idiomas (inglés y español) para mexicanos; el fortalecimiento de los programas de defensa legal para los inmigrantes a lo largo de 45 consulados en Estados Unidos y Canadá, así como la creación de ventanillas de salud en varias de estas representaciones, donde se ofrecen servicios médicos básicos. La creación del Ime representa la culminación de estos esfuerzos. El IME forma parte de la Secretaría de Relaciones Exteriores e incluye un consejo consultivo de 105 representantes de las organizaciones de migrantes en Estados Unidos y Canadá, el cual es electo en 45 distritos consulares, además de los delegados de cada uno de los 32 estados de la República mexicana (González Gutiérrez, 2005; Escobar, 2006).

Aún cuando este sistema de representación es nuevo y todavía quedan varios problemas por resolver, muestra claramente el compromiso del gobierno mexicano por establecer una presencia activa entre su amplia población de expatriados. El Estado busca demostrar, con acciones concretas, su interés en el bienestar de los migrantes y, de paso, estimular su lealtad así como sus contribuciones. Además de las actividades de los gobiernos de los estados, esta postura activa transforma el carácter del transnacionalismo inmigrante, de ser un fenómeno de las bases, a ser guiado y apoyado por las políticas junto con los programas internacionales del régimen del país de origen. Siguiendo una práctica política bien establecida en México, los funcionarios del gobierno de ese país buscan, así, incorporar a los inmigrantes y a sus organizaciones en las estructuras de patrocinio estatal. En este sentido, el actual presidente, Vicente Fox, habla de un gobierno para todos los mexicanos, independientemente de dónde residan.

El transnacionalismo es, de esta manera, bastante diferente debido a los contextos de salida e incorporación. Un flujo laboral que en su mayoría es rural, con frecuencia indígena, incluye un bajo capital humano de sus migrantes, lo que impide que se unan a formas organizacionales de clase media. No puede esperarse 
que surjan Clubes de Leones o Kiwanis de migrantes con orígenes tan modestos, los cuales ocupan posiciones en la parte baja del mercado laboral estadounidense. En cambio, se activan las lealtades y deberes tradicionales para unir a los migrantes y sostener lazos perennes con sus lugares de origen. En algunas instancias, esos lazos son tan fuertes que los inmigrantes parecen no haber dejado jamás los lugares de los que salieron. Ni siquiera los inmigrantes indocumentados lo piensan mucho para encabezar un club de oriundos y dedicarle, a él, muchas horas y dólares ganados arduamente (Smith, 2005; Roberts et al., 1999).

Un ejemplo relevante es el pueblo de San Miguel Comitipla, en el estado de Guerrero, cuyo club de oriundos en Nueva York/Nueva Jersey está incluido en la muestra. En una visita posterior a México, los miembros del equipo de investigación viajaron a Guerrero para visitar el pueblo y el área subyacente así como entrevistar a las autoridades. El primer resultado concreto, de la ayuda transnacional de los inmigrantes, fue el impresionante kiosco construido en la plaza central; después, la iglesia del pueblo fue reparada y remodelada, posteriormente se compró un reloj para su torre. La mayor parte de estos proyectos se logró gracias a las contribuciones monetarias de los migrantes y al trabajo local voluntario, siguiendo una larga tradición indígena. El más ambicioso proyecto actual es la ampliación de la plaza para que haya espacio donde celebrar las fiestas anuales. Se espera que cueste alrededor de 80 mil dólares, con un techo adicional de 260 mil dólares. Los migrantes del centro de Xochihuehuetlan, el municipio al que pertenece el pueblo de San Miguel, también han realizado sus propios proyectos. El alcalde de Xochihuehuetlan describió los inicios de esta colaboración transnacional:

Más o menos en 1985 se comenzaron las obras que beneficiaron a nuestro pueblo [...], eran de carácter religioso para mejorar el santuario de San Diego de Alcalá, que es el santo patrono más respetado en los alrededores. Luego compramos alumbrado para las calles para iluminar la avenida que lleva a éste [...], la avenida por la que pasa la procesión. En la actualidad, y con la ayuda de los migrantes en Estados Unidos, las obras públicas están muy avanzadas: la iglesia está en buenas condiciones, remodelada y con hoja de oro en los altares [...] Ahora buscamos reconstruir la escuela con apoyo del municipio, que yo presido, y de la gente que tenemos en Estados Unidos, con quien siempre tenemos buenas relaciones. ${ }^{15}$

La figura tres presenta un panorama de los lazos transnacionales internacionales mexicanos.

\footnotetext{
${ }^{15}$ Entrevista de campo realizada por el equipo de investigación en México, 2005.
} 
FIGURA 3

Conexiones internacionales y transnacionales de las organizaciones de inmigrantes mexicanos

\begin{tabular}{|c|c|c|c|c|c|c|}
\hline \multicolumn{3}{|c|}{ ESTADOS UNIDOS } & \multicolumn{4}{|c|}{ MÉXICO } \\
\hline Tipo & Ubicación & Nombre & Nombre & Ubicación & Tipo & Programas \\
\hline Político & Múltiple & Consulados $<$ & $\begin{array}{l}\text { Instituto de } \\
\text { los } \\
\text { Mexicanos } \\
\text { en el Exterior } \\
\text { (IME) }\end{array}$ & $\begin{array}{l}\text { Ciudad de } \\
\text { México }\end{array}$ & Político & $\begin{array}{l}\text { Servicios legales } \\
\text { y de salud para } \\
\text { inmigrantes } \\
\text { Cursos de idioma } \\
\text { y recursos } \\
\text { bibliotecarios } \\
\text { Representación } \\
\text { por elección de las } \\
\text { organizaciones de } \\
\text { inmigrantes ante el } \\
\text { consejo del ImE }\end{array}$ \\
\hline $\begin{array}{l}\text { Cívico/ } \\
\text { Político }\end{array}$ & $\begin{array}{c}\text { Múltiple } \\
\text { (predomina } \\
\text { en Los } \\
\text { Ángeles y } \\
\text { Suroeste) }\end{array}$ & $\begin{array}{c}\text { Confederaciones } \\
\text { de inmigrantes }\end{array}$ & & & & \\
\hline $\begin{array}{l}\text { Servicios } \\
\text { sociales }\end{array}$ & Múltiple & $\begin{array}{c}\text { Casas } \\
\text { (Puebla, } \\
\text { Guanajuato, } \\
\text { etc.) }\end{array}$ & $\begin{array}{l}\text { Gobiernos } \\
\text { estatales } \\
\text { (Zacatecas, } \\
\text { Guanajuato, } \\
\text { Jalisco, } \\
\text { Puebla, etc.) }\end{array}$ & Múltiple & Político & $\begin{array}{l}\text { Promoción de } \\
\text { federaciones para } \\
\text { todo el estado de los } \\
\text { clubes de oriundos } \\
\text { Creación de Casas } \\
\text { con el nombre del } \\
\text { estado en áreas de } \\
\text { concentración de } \\
\text { inmigrantes }\end{array}$ \\
\hline $\begin{array}{c}\text { Cívico/ } \\
\text { Filantrópico }\end{array}$ & Cientos & $\begin{array}{c}\text { Comité de } \\
\text { oriundos }\end{array}$ & $\begin{array}{l}\text { Gobiernos } \\
\text { municipales; } \\
\text { iglesias } \\
\text { locales }\end{array}$ & Cientos & $\begin{array}{l}\text { Político/ } \\
\text { Religioso }\end{array}$ & $\begin{array}{l}\text { Donaciones para } \\
\text { proyectos de } \\
\text { beneficio público y } \\
\text { religioso } \\
\text { Provisión de escuelas } \\
\text { y clínicas } \\
\text { Patrocinio de las } \\
\text { festividades anuales } \\
\text { en honor del } \\
\text { santo patrón de la } \\
\text { localidad }\end{array}$ \\
\hline
\end{tabular}




\section{CONCLUSIÓN}

Este estudio ha intentado presentar una narrativa del fenómeno del transnacionalismo inmigrante como se da en el campo, es decir, en la experiencia diaria de los migrantes y de sus contrapartes en el país de origen. Encontramos que, aunque no son universales, las actividades cívicas, filantrópicas, culturales y políticas transnacionales son comunes entre los inmigrantes en Estados Unidos y, en conjunto, tienen suficiente peso para afectar las posibilidades de desarrollo de localidades y regiones así como para atraer la atención de los gobiernos de los países de origen. Los iniciadores y líderes de estas actividades tienden a ser de mayor edad, a pertenecer al grupo de migrantes mejor establecidos con niveles de escolaridad por encima del promedio. Este hallazgo, que refuerza a aquellos de estudios cuantitativos anteriores, con fundamento en las encuestas del CIEP, indica que las lealtades y la nostalgia del terruño son duraderas y que, por lo tanto, puede esperarse que esas actividades continúen a medida que maduren las comunidades de inmigrantes. Cualquier otro carácter que adopte el transnacionalismo, no es un fenómeno asociado con lo reciente de la llegada ni está destinado a desaparecer, como parte de un proceso inexorable de asimilación (Guarnizo et al., 2003).

Una vez dicho esto, sin embargo, el principal hallazgo del estudio es el de las diferentes formas que adoptan estas actividades de una nacionalidad de inmigrantes a otra. La proposición de que los contextos de salida y recepción determinan el origen, ímpetu y carácter de las organizaciones transnacionales es fortalecida, ampliamente, por nuestros resultados. No obstante, estos hallazgos van mucho más allá de esta afirmación, al documentar en detalle las formas que adoptan estas iniciativas en las tres nacionalidades estudiadas. En síntesis, el transnacionalismo colombiano incluye clubes de oriundos, pero en su mayor parte se trata de un fenómeno de "clase media», cuya punta de lanza se sitúa en los Clubes de Leones y Kiwanis, las asociaciones de profesionistas y las filantropías católicas en Estados Unidos. Las organizaciones dominicanas también incluyen a clubes de oriundos y asociaciones de profesionistas, pero el perfil que las define es político, marcado por la naturaleza política plena de relaciones de las agencias de servicio social en esta comunidad. Finalmente, el club de oriundos es la norma entre los inmigrantes mexicanos, quienes han creado cientos de estas organizaciones, las han apoyado con contribuciones regulares y trabajo voluntario, al tiempo que han generado procesos de desarrollo duraderos y trascendentes en sus comunidades de origen. Los vínculos que unen al terruño con su gente en el extranjero son mucho más fuertes en el caso de estos migrantes rurales, frecuentemente indígenas. Tienden a generar "comunidades transnacionales» en el sentido pleno del término (Levitt, 2001).

Las diferencias nacionales se hacen evidentes, tanto en los resultados de la regresión multivariada como en los de carácter cualitativo, que constituyen 
fuertes predictores del origen y tipo de las organizaciones transnacionales, así como del alcance de su acción. En parte, las diferencias reflejan el ingreso de los gobiernos de los países de origen en el campo transnacional y las políticas que hasta el momento han desarrollado. Todos los gobiernos han mostrado un interés creciente por sus comunidades de expatriados, por ello han promovido leyes que incluyen concesiones, además de promover programas diseñados para renovar sus lealtades y hacerlos sentir parte de una comunidad nacional imaginada (Smith, 2005). Pero luego comienzan las diferencias. Los esfuerzos de los Estados colombiano y dominicano trascienden el ámbito de lo simbólico. Ambos gobiernos aparentan ser demasiado débiles y pobres para desarrollar programas a gran escala que proporcionen beneficios concretos a sus expatriados o reorganicen y marquen nuevos rumbos a sus iniciativas transnacionales. En esta situación, el principal impulso del país de origen, para la continuidad y expansión de estas actividades, proviene de otros actores: una sociedad del sector privado corporativo, en el caso de Colombia, y los departamentos de asuntos exteriores de los partidos políticos, en el caso de República Dominicana.

La experiencia mexicana es diferente, ya que implica una presencia del Estado mucho más vigorosa y activa que, tanto en los ámbitos nacional como regional, busca incorporar y guiar los ya fuertes vínculos entre una gran población de inmigrantes y sus lugares de origen. Dado que los gobiernos federal y estatal, en México, no tienen autoridad sobre los ciudadanos que viven en Estados Unidos, han buscado inducir su participación en los programas oficiales, al ofrecer una serie de beneficios que van más allá de aquellos con un mero poder simbólico. El resultado es la incorporación progresiva de muchos clubes de oriundos y de sus federaciones en estructuras de diseño oficial, como ya se mencionó, mientras que otras continúan con independencia de estos planes.

Si las organizaciones y el activismo transnacionales pueden ser tan diferentes entre tres nacionalidades de inmigrantes, que comparten las mismas raíces históricas y el mismo idioma, podemos esperar que esas variaciones se magnifiquen para los inmigrantes provenientes de otras tierras, religiones y culturas. Es imposible, con los datos disponibles, construir una tipología exhaustiva de las organizaciones transnacionales de inmigrantes, precisamente porque el estudio de este fenómeno sigue en su infancia. Algo que queda claro, a partir de la evidencia disponible, es que las múltiples actividades de los inmigrantes y de sus contrapartes en el país de origen tienen el potencial para añadirse a los rasgos de los procesos contemporáneos de la globalización, que van en contra de la lógica «multinacional» del capitalismo corporativo. Este último exacerba las desigualdades entre naciones y es indiferente, en gran parte, ante las condiciones de quienes habitan el sur del globo. Por el contrario, las actividades de los clubes de oriundos y de otras organizaciones de inmigrantes buscan, vigorosamente, mejorarlas. Como señalara agudamente un joven sociólogo salvadoreño, «la migración y las remesas son los verdaderos programas de ajuste de los pobres en estos países» (Ramos, 2002). 
La dialéctica por la cual la gente que es expulsada de sus países por la pobreza, la violencia y la falta de oportunidades da la vuelta y busca revertir estas condiciones, al utilizar los recursos adquiridos en el extranjero, necesita ser investigada con mayor detalle. Esta dialéctica ofrece, al menos, la promesa de hacer más lenta la partición del mundo entre los ricos cada vez más ricos y los pobres cada vez más pobres, debido a que la globalización capitalista ha hecho poco para reducir tal brecha. En este contexto, los pobres que migran no han tenido otra alternativa que tomar los asuntos en sus propias manos, en busca de un mejor futuro para ellos mismos y para quienes se quedan en sus pueblos.

BIBLIOGRAFÍA

AlbA, Richard y Victor Nee (2003), Remaking the American Mainstream: Assimilation and Contemporary Immigration, Cambridge, MA, Harvard University Press.

Basch, Linda G., Nina Glick-Schiller y Cristina Blanc-Szanton (1994), Nations Unbound: Transnational Projects, Post-Colonial Predicaments, and De-Territorialized Nation-States, Langhorne, PA, Gordon and Breach.

Bourne, Randolph S. (1916), "Transnational America», en The Atlantic Monthly, julio, pp. 86-97.

Castles, Stephen (2004), "The Factors that Make and Unmake Migration Policies», en International Migration Review, 38, otoño, pp. 852-884.

Cornelius, Wayne A. (1998), «The Structural Embeddedness of Demand for Mexican Immigrant Labor: New Evidence from California», en Crossings: Mexican Immigration in Interdisciplinary Perspective (edición de M. Suárez-Orozco), Cambridge, Center for Latin American Studies, Harvard University, pp. 115-155.

CortinA, Jerónimo y Rodolfo de la Garza (2004), Immigrant Remitting Behavior and its Developmental Consequences for Mexico and El Salvador, Los Ángeles, The Tomás Rivera Policy Institute.

Escobar, Cristina (2003), «Various Routes to Dual Citizenship and Extraterritorial Political Rights: The Colombian Experience in the Latin American and Caribbean Context», paper presented at the 2003 meetings of the American Sociological Association, Atlanta.

(2004), «Dual Citizenship and Political Participation: Migrants in the Interplay of United States and Colombian Politics», en Latino Studies, núm.

2, pp. 45-69. (2006) (en prensa), «Migration and Citizen Rights: The Mexican Case», en Citizenship Studies, núm. 10 (5), septiembre.

Evans, Peter (2000), «Fighting Marginalization with Transnational Networks: Counter-Hegemonic Globalization», en Contemporary Sociology, núm. 29, pp. 230-241. 
GLICK Schiller, Nina (1999), "Transmigrants and Nation States: Something Old and Something New in the U.S. Immigrant Experience», en Handbook of International Migration, the American Experience (edición de C. Hirschman, P. Kasinitz y J. DeWind), Nueva York, Russell Sage Foundation, pp. 94-119.

GLICK Schiller, Nina y Georges Fouron (1999), «Terrains of Blood and Nation: Haitian Transnational Social Fields», en Ethnic and Racial Studies, núm. 22 (marzo), pp. 340-66.

Goldring, Luin (2002) «The Mexican State and Transmigrant Organizations: Negotiating the Boundaries of Membership and Participation", en Latin American Research Review, núm. 37, pp. 55-99.

GonzÁlez Gutiérrez, Carlos (1999), «Fostering Identities: Mexico's Relations with its Diaspora», en Journal of American History, núm. 86 (septiembre), pp. 545-567.

(2005), «Mexico's Relation to its Diaspora», keynote address to the Hispanic Summit of the Plains conference, sponsored by the Office of Latin and Latino Affairs (OLLAS), University of Nebraska-Omaha, Omaha, Nebraska, abril.

Gordon, Milton M., (1964), Assimilation in American Life: The Role of Race, Religion, and National Origins, Nueva York, Oxford University Press.

Grasmuck, Sherri y Patricia Pessar (1991), Between Two Islands: Dominican International Migration, Berkeley, University of California Press.

Guarnizo, Luis E. (2003), "The Economics of Transnational Living», en International Migration Review, núm. 37, otoño, pp. 666-699.

Guarnizo, Luis E. y Luz M. Díaz (1999), «Transnational Migration: A View from Colombia», en Ethnic and Racial Studies, núm. 22, pp. 397-421.

Guarnizo, Luis E., Alejandro Portes y William Haller (2003), "Assimilation and Transnationalism: Determinants of Transnational Political Action among Contemporary Immigrants», en American Journal of Sociology, núm. 108, mayo, pp. 1211-1248.

Guarnizo, Luis E., Arturo I. Sanchez y Elizabeth Roach (1999), «Mistrust, Fragmented Solidarity, and Transnational Migration: Colombians in New York and Los Angeles», en Ethnic and Racial Studies, núm. 22, marzo, pp. 367-396.

Itzigsohn, José y Silvia G. Saucedo (2002), «Immigrant Incorporation and Socio-cultural Transnationalism", en International Migration Review, núm. 36, otoño, pp. 766-798.

Itzigsohn, José, Carlos Dore, Esther Fernandez y Obed Vazquez (1999), «Mapping Dominican Transnationalism: Narrow and Broad Transnational Practices», en Ethnic and Racial Studies, núm. 22, marzo, pp. 316-339.

KeCK, Margaret y Kathryn Sikkink (1998), Activists beyond Borders, Ithaca, NY, Cornell University Press.

Kyle, David (2000), Transnational Peasants: Migration, Networks, and Ethnicity in Andean Ecuador, Baltimore, Johns Hopkins University Press. 
LANDOLT, Patricia (2001), «Salvadoran Economic Transnationalism: Embedded Strategies for Household Maintenance, Immigrant Incorporation, and Entrepreneurial Expansion", en Global Networks, núm. 1, pp. 217-242.

LaTin American Weekly Report (2003), «Remittances: Year's Total Exceed Forecast», 4 de noviembre, wR-03-43.

LevitT, Peggy y Nina Glick Schiller (2004), "Conceptualizing Simultaneity: A Transnational Social Field Perspective on Society», en International Migration Review, núm. 38, otoño, pp. 1002-1039.

LevitT, Peggy (2001), The Transnational Villagers, Berkeley, University of California Press.

López, David E. y Ricardo D. Stanton-Salazar (2001), «Mexican-Americans: A Second Generation at Risk», en R. G. Rumbaut y A. Portes (eds.), Ethnicities: Children of Immigrants in America, Berkeley, CA, University of California Press y Russell Sage Foundation, pp. 57-90.

Massey, Douglas S., Jorge Durand y Nolan J. Malone (2002), Beyond Smoke and Mirrors: Mexican Immigration in an Era of Economic Integration, Nueva York, Russell Sage Foundation.

Merton, Robert K. (1968), Social Theory and Social Structure, Nueva York, The Free Press.

Orozco, Manuel (2003), "Hometown Associations and their Present and Future Partnerships: New Development Opportunities», reporte, Washington, DC, U.S. Agency for International Development.

Portes, Alejandro (2003), «Theoretical Convergencies and Empirical Evidence in the Study of Immigrant Transnationalism», en International Migration Review, núm. 37, otoño, pp. 874-892.

Portes, Alejandro y Josh DeWind (2004), "A Cross-Atlantic Dialogue: The Progress of Research and Theory in the Study of International Migration», en International Migration Review, núm. 38, otoño, pp. 828-851.

Portes, Alejandro y Luis E. Guarnizo (1991), «Tropical Capitalists: U.S.-Bound Immigration and Small Enterprise Development in the República Dominicana», en Migration, Remittances, and Small Business Development: Mexico and Caribbean Basin Countries (edición de S. Diaz-Briquets y S. Weintraub), Boulder, co, Westview Press, pp. 101-131.

Portes, Alejandro, Luis E. Guarnizo y Patricia Landolt (1999), «Transnational Communities: Pitfalls and Promise of an Emergent Research Field», en Ethnic and Racial Studies, núm. 22, pp. 217-237.

Portes, Alejandro, William Haller y Luis E. Guarnizo (2002), «Transnational Entrepreneurs: An Alternative Form of Immigrant Adaptation», en American Sociological Review, núm. 67, abril, pp. 278-298.

Ramos, Carlos Guillermo (2002), «Rapporteurs Comments Delivered at the Conference on Immigrant Transnationalism and its Impact on Sending Nations», Sponsored by the Center for Migration and Development, Princeton 
University and Latin American School of Social Science (FlaCSO), Santo Domingo, D.R., enero.

RoBerTs, Bryan R., Reanne Frank y Fernando Lozano-Asencio (1999), «Transnational Migrant Communities and Mexican Migration to the United States», en Ethnic and Racial Studies, núm. 22, marzo, pp. 238-266.

SMITH, Robert C. (2003), «Diasporic Memberships in Historical Perspective: Comparative Insights from the Mexican, Italian, and Polish Cases», en International Migration Review, núm. 37, otoño, pp. 724-759.

(2005), Mexican New York: Transnational Lives of New Immigrants, Berkeley, CA, University of California Press.

U.S. Bureau of the Census (2001), The Hispanic Population 2000, Census Brief, Washington, DC, U.S. Department of Commerce.

Vertovec, Steven (2004), «Migrant Transnationalism and Modes of Transformation», en International Migration Review, núm. 38, otoño, pp. 970-1001.

WaLDINGER, Roger y David Fitzgerald (2004), «Transnationalism in Question», en American Journal of Sociology, núm. 109, pp. 1177-1196.

Warner, W. Lloyd y Leo Srole (1945), The Social Systems of American Ethnic Groups, Nueva Haven, Yale University Press.

Zolberg, Aristide (1989), "The Next Waves: Migration Theory for a Changing World», en International Migration Review, núm. 23, pp. 403-430. 